\title{
JG|u
}

Gutenberg School of Management and Economics

\& Research Unit "Interdisciplinary Public Policy"

Discussion Paper Series

\section{Emotion Research in Economics}

Klaus Wälde

June 2016

\section{Discussion paper number 1611}


Contact details

Klaus Wälde

Chair in Macroeconomics

Johannes Gutenberg-University Mainz

Jakob-Welder-Weg 4

55128 Mainz

waelde@uni-mainz.de 


\title{
Emotion Research in Economics
}

\author{
Klaus Wälde ${ }^{1}$ \\ Johannes-Gutenberg University Mainz and CESifo \\ June 2016
}

\begin{abstract}
Emotions were central to the development of economics, especially in utility theory in classical economics. While neoclassical utility theory basically abolished emotions, behavioural economics more recently reintroduced emotions in utility theory. Beyond utility theory, economic theorists use emotions to explain behaviour which otherwise could not be understood or they study emotions out of interest for the emotion itself. While some analyses display a strong overlap between psychological thinking and economic modelling, in most cases there is still a large gap between economic and psychological approaches to emotion research. Ways how to reduce this gap are discussed.
\end{abstract}

Keywords: utility theory, ex-ante emotions, immediate emotions, ex-post emotions belief-based emotions, regret, desire, stress, anxiety, guilt

\footnotetext{
${ }^{1}$ Klaus Wälde, Johannes-Gutenberg University Mainz, Mainz School of Management and Economics, JakobWelder-Weg 4, 55131 Mainz, Germany. Phone + 49.6131.39-20143, waelde@uni-mainz.de, www.waelde.com. I am very grateful to Carlos Alós-Ferrer, Andrew Caplin, Andreas Eder, Jürgen Eichberger, Christian Gollier, Ennio Stacchetti, Peter Wakker and especially Agnes Moors for discussions and very constructive and helpful comments.
} 


\section{Pleasure and pain are undoubtedly the ultimate objects of the Calculus of Economics \\ W. Stanley Jevons $(1871,1957$, p. 37)}

\section{Introduction}

Motivation - Why should a psychologist be interested in how emotions are used and studied in economic analysis? ${ }^{2}$ Maybe out of pure curiosity. Then a psychologist could be interested in learning that economists analyse almost all aspects of society. Obviously, economists analyse determinants of economic growth, of business cycles or of international trade. They study effects of monetary policy, government debt and taxation and the origins of material inequality and unemployment. They investigate into the behaviour of firms and how individuals behave in economic situations. If economics stopped there, there would be non need to promote emotion research in economics. As long as economists restrict the application of their decision models to pure economic choices, like the spending of money among various consumption goods or investment decisions of firms, emotion-free models would be appropriate to understand decision making.

But economic analysis goes much beyond these fields. Economists analyse crime, family behaviour, excessive consumption behaviour and addiction, bargaining behaviour, divorce, political campaigns and (the list could be extended) strategic interaction between two individuals or in small groups. And this is where the necessity of introducing emotions into economic analyses originates. If decision making by economists was restricted to highly aggregate macroeconomic situations or to situations where only costs and benefits play a role, the standard model would be sufficient. But the more micro-economic an analysis becomes, the larger the problems, the more pressing the need for emotions to be taken into account. These arguments hopefully clearly show that economic thinking needs psychological knowledge if economics should move towards are more human and humane model of man.

But could there be some other motivation beyond pure curiosity why a psychologist should be interested in emotion research in economics? One motivation could be that emotion research in psychology might learn from emotion research in economics. Anticipating the main findings of this survey, such a learning cannot be grounded on the contents. Very many if not all psychological ideas in economic emotion research come from psychology. Many authors write statements like "we use psychological evidence to support our findings" or "these aspects have been discussed in the psychological literature". What is of course genuine to economic analysis is (i) the belief in some type of optimizing behaviour of individuals and (ii) the formal mathematical structure used in economic analysis. If a psychologist therefore continues reading this survey beyond this point, it could be (a) because of some pleasure in seeing how psychological knowledge is used elsewhere or it could be (b) because of some interest in formal methods and an interest in understanding how they can be used to better understand emotions.

Here is an argument why formal methods help: Paul Samuelson (1915 - 2009), winner of the Nobel Prize in Economic Sciences in 1970, was once asked whether mathematics is needed in economic analysis. He replied" ${ }^{3}$ "No, of course not. You can do economics without mathematics. You simply need to be so much brighter." Imagine one wants an answer to a certain question (e.g. the implication of a certain emotion on human behaviour) at a given level of differentiation and sophistication concerning behavioural predictions. Imagine further a mathematical analysis can provide this after, say, 10 days of research. Then the Samuelson

\footnotetext{
${ }^{2}$ This paper was originally written as an invited review for the Emotion Review. This original version contains much more material than the version which eventually appeared as Wälde and Moors (2016).

${ }^{3}$ The importance of Samuelson for popularizing mathematics in economics is praised by Glaeser (2009). See also the introduction of the more comprehensive honoring of his work in Dixit (2012).
} 
quote states that a non-mathematical analysis would require much more than these 10 days of research. We therefore offer two reasons why emotion research in economics is of interest to psychologists. First, it shows how important psychology is to other sciences. Second, it shows how important mathematics is to economics. ${ }^{4}$

A definition - Writing a paper on a certain issue (emotions) in a certain field (economics) asks for a definition of what one talks about (emotions) and what the field is (economics). This is a formidable task in itself given the huge literature on what emotions actually are - just think of papers like Kleinginna and Kleinginna (1981) that presents and discusses a list of 92 definitions of emotions. Asking what economics and its various fields are similarly fills libraries. Interested readers can start e.g. from Lawson (2013) who studies the difference between classical economics and neoclassical economics and concludes that "the term 'neoclassical economics' should be dropped from the literature" (p. 980).

How should one then ever find out what emotion research in economics is about? We make three pragmatic decisions. In this paper, an emotion is what people call an emotion: Employing the first five words from the left on the ISRE homepage, i.e. hope, confusion, anger, love and surprise would then be examples of emotions. A somewhat longer list can be found e.g. in Shaver et al. (1987), reproduced in appendix A.1. ${ }^{5}$ The advantage of following this prototype approach (as opposed to various other theoretical perspectives on emotions, see e.g. the special issue introduced by Russell, 2014) is that it produces precise expressions (the words for certain emotions) that can be used to identify emotion research. ${ }^{6}$

The second pragmatic decision consists in defining economics as the field that is represented in publications in "core journals". While one could again spend a lot of time thinking about what a core journal is (see e.g. the discussions in Kalaitzidakis et al., 2003, Axarloglou and Theoharakis, 2003, and Liner, 2002), we take a "standard" list of 34 (see appendix A.2) journals that have the highest impact factors in economics. "Current emotion research in economics" is then by definition represented by articles in these economic journals that contain an emotion word. ${ }^{7}$

Our third pragmatic decision induces us to focus on emotion theory in economics. Science proceeds by a permanent interaction between theory and data and it seems idle to discuss what comes first or what is more important. Theory informs empirical analysis how to define data, what data to look for and how to provide interpretations to empirical regularities. Data informs theory about relevant questions, about the magnitude of various determinants and eventually judges about success and failure of theoretical ideas. The reason to focus on theoretical work is twofold. First, given the author's research background, he is better at describing theoretical analyses than empirical analyses. Second, the author holds the (possibly biased) view that emotion research would benefit more from better theoretical foundations than from more empirical analysis.

The open question - Our overview of current emotion research in economics is organized around three questions. First, which role do emotions play in utility theory? We provide an answer to this question even though we depart somewhat from what one usually understands as "current". We look at utility theory in classical economics, in neoclassical economics and

\footnotetext{
${ }^{4}$ Maybe there is a "second b" that shows how useful mathematics could be for other disciplines. But it is probably up to future work, in the ideal case to be undertaken by a economist-psychologist team, to provide convincing evidence.

${ }^{5}$ An alternative and more recent list is in Sacharain et al. (2012). It also links emotion words to valence and arousal and thereby builds a bridge to the more continuous approach to emotions.

${ }^{6} \mathrm{We}$ are aware that this is a very psychology-driven definition of emotions. This implies that e.g. fairness and altruism are not considered as emotions. In economic analyses, however, these terms are often associated with emotions.

${ }^{7}$ Given this definition, we grant ourselves some liberty to add one or another prominent or promising paper from a book, some other journal or other.
} 
in behavioural economics. We take this in part historical digression as current discussions in economics can best be understood with some historical background.

Our second question forms the core of this survey: How do economists study emotions (beyond utility theory)? We will see that a whole range of emotions is the object of current research: anticipatory emotions like anxiety and suspense, instantaneous emotions including hunger ${ }^{8}$ craving or stress and ex-post emotions like disappointment or elation. In a certain class of models, emotions are seen as subjective beliefs of individuals.

Finally, we would like to understand what one can learn from these economic analyses. We provide an answer for economists (a lot) and for psychologists (to be seen). The answer for economics directly follows from reading the introductions and conclusions of the corresponding articles. Answers for psychology are more speculative as methodological knowledge in economics would have to be applied more in psychology in order to see whether this could yield any benefits.

Related literature. Emotion research in economics is a subfield - which could be called 'emotional economics' - of behavioural economics. Including neuro-economics and boundedrationality into behavioural economics, this field can be approached via textbooks (e.g. Dhami, 2015, Wakker, 2010), entries in encyclopedias (Mullainathan and Thaler, 2001), surveys (Camerer and Loewenstein, 2004, Fudenberg, 2006, Rabin, 2013, Harstad and Selten, 2013), research books (Camerer et al., 2003 ) and books containing methodological discussions (Caplin and Schotter, 2008). The advantage of the present paper over these books and surveys is the focused overview of emotion research. While a very up-to-date overview of emotion research is also provided by Dhami (2015, ch. 6), the latter is much more technical and more appropriate for a highly advanced masters course or $\mathrm{PhD}$ programme in economics. Our survey is more of an introductory nature providing more of an overview and general understanding.

There are three surveys that cover emotions and economics in the economics literature. Elster (1998) provides (inter alia) a background from psychology, discusses whether emotions can be chosen and how emotions interact with other motivations (like maximizing self-interest) in determining behaviour. DellaVigna (2009) looks at field evidence for behaviour as described by behavioural economics. In ch. 4.5 he looks at two examples of emotions, mood and arousal. Our survey puts more emphasis on conceptual issues and modelling and relates the current discussion of utility theory with classic economics. Loewenstein (2000) provides a very short survey that focuses on immediate emotions and visceral factors. We return to his analysis further below when looking at 'hunger' and 'thirst'.

Surveys which probably come closest to ours are available in the psychological literature. Loewenstein and Lerner (2003) and Rick and Loewenstein (2008) provide extensive discussions of various approaches on the "role of affect in decision making" and on the "role of emotions in economic behaviour". Ours differs in its more formal approach that allows a more detailed understanding of how economists perceive emotions.

Table of contents - The rest of this paper provides answers to our three questions formulated above. The next section looks at the first question of the role of emotions in utility theory. The main part of this survey is formed by section 3 that looks at how economists analyse emotions and their effect on decision making. Section 4 will take up the third question on what economics and psychology can learn from emotion research in economics. The final section concludes.

\footnotetext{
${ }^{8}$ Hunger and thirst are usually understood as motivations or drives, not as emotions. Yet, they can be seen as a source of emotions or it can be argued (Loewenstein, 2000, p. 426) that their effects are similar to negative emotions. See below for more discussion.
} 


\section{The role of emotions in utility theory}

This section studies the role emotions play when economists talk about utility. ${ }^{9}$ In classical economics (sect. 2.1), utility was clearly perceived as a measure of an individual's feeling. Decision theory in neoclassical economics (sect. 2.2) provides a framework that allows to predict human behaviour without any reference to emotions. Behavioural economics (sect. 2.3) provides interpretations of utility that also allow for a hedonic perspective. For this field, it is probably fair to say that two research programmes coexist: One in which emotions are by construction nonexistent (and not allowed) and one where emotions are routinely taken into account. When we look at altruism and fairness (sect. 2.4), one can argue that these analyses have some idea of a feeling in the background, but they do not explicitly highlight and study these emotional aspects.

\subsection{Utility and emotions in classical economics}

Asking what role of emotions play in economics requires fixing which period of economics one looks at. Most naturally, one would want to understand the role in contemporary economics. Some of the current debates, however, cannot fully be understood without some historical background. We therefore briefly talk about the role emotions played since the beginning of economic theory. ${ }^{10}$

The natural place to look for emotions in economic thinking is the field of 'utility theory'. Utility theory is the basis of any description or theory of decision making which requires a comparison of values of different objects. One would therefore expect economists to work with some notion of an emotion in this context.

The term utility was introduced into economics by Adam Smith (1776) in his "The Wealth of Nations" to describe the "value in use" of a certain good. This differs from an alternative characteristic of a good, its "value in exchange" (see Stigler, 1950a, p. 307). ${ }^{11}$ It was left to Jeremy Bentham, however, to make utility a popular concept. His "Introduction to the principles of morals and legislations" $(1789,1970)$ contains the famous statement that "Nature has placed mankind under the governance of two sovereign masters, pain and pleasure" (p. 11, italics in original). His analysis then continues inter alia with various sections containing discussion of types of pleasures (e.g. from wealth, skill, power, expectation and relief) and pains (e.g. of desire, disappointment, regret and expectation).

The importance of understanding feelings was expressed even more forcefully by W. Stanley Jevons $(1871,1957)$ in his "Theory of Political Economy". After devoting an entire chapter on the "Theory of pleasure and pain" he defines utility in the subsequent chapter "to denote the abstract quality whereby an object serves our purposes". This object will then "afford pleasure or ward off pain" (both quotes from p. 38) to its user. A phrase less well-known than the one by Bentham but much stronger in stressing what economics is all about introduces his chapter on utility: "Pleasure and pain are undoubtedly the ultimate objects of the Calculus of Economics" (p. 37).

One could continue with many further examples and more detailed presentations of the strong link between emotions and utility theory in classic economics. As this survey is more on

\footnotetext{
${ }^{9}$ The study of the history of the concept of utility is of course broader. As a starting point, see Stigler (1950a, b) and Abdellaoui, Barrios and Wakker (2007, sect. 2 and 3).

${ }^{10}$ For related arguments, see e.g. Stigler (1950a,b) Frey and Stutzer (2002), Berridge and O'Doherty (2014) or the introduction of Loewenstein (2000).

${ }^{11}$ Before Smith, Bernoulli $(1738,1954)$ had used the term utility in his analysis of risk and of the question how to evaluate a gamble. He also distinguished the price of a good from its value, which he defined as the utility the good yields. Interestingly, he saw utility as a concept which takes particular circumstances of a person (e.g. how rich a person is) into account.
} 
current emotion research, we only allow ourselves a last digression to an analysis of Edgeworth $(1881,1967)$. It is another good example for the fundament on which the revival of classic thinking in modern economics, that we will get to know further below, is being built upon. In Edgeworth's definition (p. 56) and mathematical equations for utility or social welfare functions (p. 67), he describes the utility functions as measuring pleasure (which is a "preferable feeling") and maximizing a social welfare function is understood as achieving the "greatest possible happiness" (p.67).

\subsection{Utility without emotions - the neoclassical view}

One of the reasons why utility as used in contemporaneous economics is often argued to be free of any notion of a feeling was already present in the discussion of that time. The introduction of the concept of utility into economics was accompanied by a discussion how utility could be measured and whether utility can be compared across individuals. Jevons strongly denied that utility could be measured stating that "we can hardly form the conception of a unit of pleasure or pain" and that the idea of "quantities of feelings" is out of question (Stigler, 1950a, p. 317).

Neoclassical economics, understood as economics as taught in 'standard' textbooks in 'most universities', consequently developed theories of decision making that are free of any relationship to feelings. There are two alternative approaches to decision making: the 'preference-based approach' and the 'choice-based' approach (Mas-Colell et al., 1995, ch. 1). If one wants to understand who homo oeconomicus is and how he, she or it decides, these approaches are the ones that describe it best. These two concepts (that form the basis of the field of decision theory) are the most detailed and the most microeconomic approach to human behaviour that exists in economics. ${ }^{12}$

- The preference-based approach

In the preference-based approach, the starting point of describing human beings are 'preference relationships' that describe tastes of individuals. Such a preference relationship could state for a certain individual e.g. that a consumption bundle $x$ (consisting e.g. of 5 loafs of bread of and 3 bowls of ice-cream) is at least as good as a consumption bundle $y$ (consisting e.g. of 4 loafs of bread of and 4 bowls of ice-cream). Symbolically, this is represented by $x \succsim y$. Any real world individual would then be described by a very large number (if not infinitely many) of preference relationships. ${ }^{13}$ These preference relationships can then be represented by a utility function $u($.$) if and only if utility from x$ is at least as large as utility from $y$, i.e. if and only if $u(x) \geq u(y)$. Predictions about human decision making are then possible by endowing homo oeconomicus with a certain amount of resources (labour income, capital income, wealth, valuable goods), informing him/her about prices of the goods and letting him maximize utility. ${ }^{14}$

Are there any emotions in this approach to human decision making? The standard interpretation is definitely a clear 'no'. As Varian (1992) in his classic microeconomics textbook puts it "A utility function is often a very convenient way to describe preferences, but it should not be given any psychological interpretation" (p. 95). One the other hand, thinking an instant about

\footnotetext{
${ }^{12}$ Developing a parallel concept in psychology leading to a 'homo psychologicus' would probably be a very promising research programme.

${ }^{13}$ The above example says that the bundle $(5,3)$ is preferred to $(4,4)$. The next preference relationship would compare $(5,3)$ to $(4.1,4)$, then to $(4.2,4)$ and so on.

${ }^{14}$ One of the many intermediate steps we skip here due to space constraints is nevertheless worth being mentioned: Preference relationships need to satisfy various properties which are axiomatically assumed. Two of them (transitivity and completeness) are usually used to define rationality. One of the advantages of formal models of human decision making is therefore that concepts used in many discussions have a very precise meaning which should help make discussions more insightful.
} 
what is really behind the symbol $\succsim$, inquiring into one's intuition about what "at least as good as" means or reading that some authors (from decision theory) talk about preference relationships as "tastes", one would immediately conclude that the symbol $\succsim$ represents feelings. If I prefer ice-cream to bread or a sweet papaya to a chocolate bar, then this means that I have a more positive hedonic experience when eating the papaya as when eating a chocolate bar. In other words, understanding feelings of individuals with respect to different consumption goods could provide a psychological micro-foundation of economic preference relationships. ${ }^{15}$

- The choice-based approach

An alternative approach to the theory of human decision making in economics is provided by the choice-based approach that goes back to Samuelson (1947). The starting point according to this view are 'revealed preference relationships' where the emphasis is on "revealed". The relationships for an individual would then state that a certain consumption bundle $x$ is revealed preferred to a consumption bundle $y$ (symbolically, this is often expressed as $x \succsim^{*} y$ ). The big difference to the preference-based approach lies in the fact that the preference relationship $\succsim^{*}$ is defined with respect to observables and not with respect to tastes of an individual: A consumption bundle $x$ is revealed preferred to $y$ if an individual chooses $x$ if both $x$ and $y$ are affordable by the individual (technically, a choice function identifies $x$ if both $x$ and $y$ are in the budget set). As Mas-Colell et al. (1995) put it, "theory of individual decision making need not be based on a process of introspection but can be given an entirely behavioral foundation". More broadly speaking, the choice-based approach to individual decision making in economics is the incarnation of positivism in the philosophy of science as is behaviourism in psychology. In fact, some economists argue (Brandstätter et al., 2010) that economics is now ready (or maybe currently undergoing) a cognitive revolution as psychology has been doing already for quite a while.

Summarizing, the choice-based approach is definitely an approach where feelings do not play a role in the analysis of human decision making. This does lend this approach quite some attractiveness as measurement issues encountered to test theories in this tradition are much weaker as compared to theories that employ some reference to feelings. On the other hand, the focus on choice-data as the only admissible data to be used for testing theories (and thereby also for guiding the elaboration and extension of existing theories) might be too restrictive. ${ }^{16}$

Looking at the choice-based and preference-based approach jointly, it seems fair to conclude that feelings do not play any practical role in these two approaches. Homo oeconomicus when modelled in this way following the usual interpretation for consumption bundles (for exceptions see below) is an emotion-free, cold and, maybe to some, a pretty scary non-human object.

- The "standard" economic decision model under risk

The models of decision making discussed so far did not refer to any potential source of uncertainty or risk. In fact, the discussion so far can be best understood when having a deterministic world in mind. As a reference point, allowing us to better understand emotionrelated decisions, we now look at expected utility theory and thereby define what is usually understood as the standard economic decision model under risk. ${ }^{17}$

\footnotetext{
${ }^{15}$ The literature on attitude and attitude change (e.g. Petty, Wheeler and Tormala, 2003, Gawronski and Bodenhausen, 2006 and Maio and Haddock, 2015) would probably be a good place to start.

${ }^{16}$ There is a very lively debate about this issue in the context of non-choice data that comes from neurological and neuroeconomic analyses (see Caplin and Schotter, 2008).

${ }^{17}$ In economic decision theory, a distinction, going back to Knight (1921), is drawn between risk (probabilities are objectively given) and uncertainty (probabilities are subjective), see e.g. Gilboa (2009). Unfortunately, this distinction sometimes seems blurred in economic analyses beyond decision theory.
} 
Assume that the world can be perceived as a random variable that can take different realizations or states. As an example, imagine that the only aspect of the world that changes is the weather and that the weather can be rainy, cloudy or sunny. At any given moment, the world is in a 'true state', i.e. it is either rainy, or cloudy or sunny (but nothing in between). Imagine further that there is some decision to be made before the weather is known (e.g. spend next Sunday outdoors or indoors). The decision consists of selecting either choice 1 (book an outdoor event) or choice 2 (stay at home). ${ }^{18}$ Each choice implies a certain utility $c_{i j}$ where $i$ stands for the choice and $j$ stands for the state of the world. To illustrate, $c_{12}$ is the utility from the outdoor event in case of cloudy weather and $c_{23}$ is the utility from staying at home when the sun shines. Finally, let probabilities for the three states of the world be objectively given. They are given by the probability $p_{1}$ that it is rainy, $p_{1}$, by the probability $p_{2}$ that it is cloudy and by the probability $p_{3}$ that it is sunny, $p_{3}=1-p_{1}-p_{2}$.

Given this framework and assuming that a certain set of axioms is satisfied, ${ }^{19}$ utility $U_{i}$ from a choice $i$ is is given by the von Neumann and Morgenstern (1944) representation,

$$
U_{i}=\Sigma_{j=1}^{3} p_{j} c_{i j}
$$

This means that utility of the individual from choice $i$ is given by the sum of utilities $c_{i j}$ from this choice under the various weather conditions $j$, weighted by the probability that this weather will actually realize. An individual will then select choice 1 if it yields higher utility than choice 2 , i.e. if $U_{1}>U_{2} \cdot{ }^{20}$

\subsection{Decision utility vs. experienced utility in behavioural economics}

Consciously or not, the most widely held view of economists about utility is the emotion-free view. As Kahneman, Wakker and Sarin (1997, p. 375) put it, "Utility is inferred from observed choices and is in turn used to explain these choices." There is no need to think about whether utility is a feeling, leave alone what type of feeling this is. It is a construct, which is not and even does not need to be observed.

\section{- Behavioural economic theory}

While this might be the dominating view, ${ }^{21}$ behavioural economic analyses have long given alternative interpretations to utility functions. ${ }^{22}$ When we think e.g. of regret and disappointment theory of Loomes and Sugden (1982, 1986), to be covered in more detail below, modern authors have very often talked about utility functions as experienced utility. They put

\footnotetext{
${ }^{18}$ The choice is assumed to be irreversible. Hence, the choice 'spend Sunday indoors' does not allow to book an outdoor event in case weather conditions turn out to be good on Sunday.

${ }^{19}$ For details see microeconomic textbooks such as Mas-Colell et al. (1995, ch. 6).

${ }^{20}$ The next step in generalizing this expected utility theory consists in allowing for subjective probabilities as in Savage (1954) yielding subjective expected utility theory. We will get to know some further extensions further below. Many more extensions exist which go far beyond emotion research. See Gilboa (2009), Wakker (2010) and Dhami (2015) as starting points.

${ }^{21}$ Without having done a representative survey, this view is actively defended probably by a small share of all economists. Most economists use the concept of utility maximization for the many economic questions to be answered. The details of utility theory play a minor role in these studies. It would be interesting to formulate questions for and to see representative answers from economists on what is actually a dominating view. Maybe an answer is even not important as long as different research programmes in the sense of Lakatos can coexist peacefully and maybe even mutually enrich each other.

${ }^{22}$ This does not mean that all of behavioral economics by definition endorse alternative views. Behavioural economic analyses comprises both analyses that stay entirely within the boundaries of revealed preference and analyses which strongly depart from this normative view. Again, see Caplin and Schotter (2008) for the current debate.
} 
themselves in the tradition of Bernoulli and Marshall and see a utility function $u($.$) as "the$ psychological experience of pleasure that is associated with the satisfaction of desire" (Loomes and Sugden, 1982, p. 807). To make arguments precise, let us define utility as experienced utility if utility does not only depend on observable choices (in the sense of the choice-based approach described above, do others observe me consuming papaya or a chocolate bar?) but also on subjective feelings or beliefs. ${ }^{23}$ In this sense, the analyses of Caplin and Leahy (2001) on anticipatory emotions, Wälde (2015) on stress or psychological game theory, all covered further below, take an experienced utility view on utility functions.

Interestingly, other areas of economic theory, which are usually far from being suspected to pursue non-neoclassical research objectives, would then also employ an experienced-utility interpretation of utility functions: There are models of unemployment where unemployed workers need to actively search for a job. They can put effort into finding a job (e.g. by writing more or better applications) to increase their probability of success. These models then typically display costs from search effort which decreases utility. ${ }^{24}$ These costs are often described as psychic costs and are hard to be objectively measured.

In all of these models from behavioural economic theory, experienced utility and decision utility are still the same object. They differ from the standard model as they allow for a hedonic interpretation of utility. But one can still provide a decision theoretic foundation of these utility functions. ${ }^{25}$ Kahneman, Wakker and Sarin (1997) go one step further and stress that decision utility and experienced utility usually fall apart in reality and must therefore be treated as different objects in theory. In their theoretical study, they employ five different types of utility: Three types of experienced utility (instant, remembered and predicted instant), total utility and decision utility. Instant experienced utility is an hedonic and affective feeling resulting from the current situation ("outcome" in their paper) of an individual where the situation includes current consumption, health, social status and other. Remembered utility is then what an individual recalls (potentially in a biased way) of pleasure and displeasure associated with past situations. Total utility is a normative concept and sums up instant experienced utilities. Total utility should be maximized by individuals if they want to maximize subjective hedonic wellbeing. Finally, decision utility is inferred from choices and does not necessarily coincide with total utility. Conceptually, it would be a function of predicted instant utility.

Formally (and neglecting some of the details like "temporary extended outcomes"), we can summarize this by

$$
U(t)=\int_{t}^{\infty} e^{-\rho[\tau-t]} u(c(\tau)) d \tau
$$

where $u($.$) is instant utility from consumption c(\tau)$ and $U(t)$ is total utility. ${ }^{26}$ Remembered utility in $\tau$ of pleasure from consumption in $s<\tau$ is then $v(u(c(s)), \tau)$. Decision utility $D(t)$ in $t$ is then something more complex which builds on predicted utility $\tilde{u}($.$) . Predicted utility$ in $t$ about consumption $c(\tau)$ in $\tau>t$ builds on utility remembered in $t$ as this is the only information available at $t$. We therefore write it as $\tilde{u}(v(u(c(s)), t), c(\tau))$. Decision utility can therefore be written as

$$
D(t)=\int_{t}^{\infty} e^{-\rho[\tau-t]} \tilde{u}(v(u(c(s)), t), c(\tau)) d \tau
$$

\footnotetext{
${ }^{23}$ Slightly more technically speaking, one would define a utilty function as an experienced utility function if the utility function contains arguments which are not objectively observable.

${ }^{24}$ Costs are required as otherwise more effort would only have positive effects. Individuals would not face a trade-off in their choice of optimal effort and no well-defined optimal behaviour exists.

${ }^{25}$ I am grateful to Andrew Caplin for discussions of this point.

${ }^{26}$ This expression is structurally identical to the standard neoclassical intertemporal objective function. The only difference consists in the interpretation that $u($.$) is a measure of a feeling of a person.$
} 
In words, consumption $c(\tau)$ for some future point in time is chosen (or at least planed to be chosen, time inconsistency can easily be imagined to occur in such a structure) on the basis of what this individual remembers in $t$ of pleasure of this type of consumption that took place earlier in $s<t .^{27}$

What is missing to make this tractable for predicting e.g. consumption-saving choices is a theory of remembered utility. While one could simply assume that remembered utility equals instant utility times a random factor $\phi$, i.e. $v(u(c(s)), \tau)=\phi u(c(s))$, this factor $\phi$ is probably not purely random but follows some systematic rules.

The probably biggest challenge to choice-based approaches to decision making emerging from this approach consists of two aspects: First, the distinction between what makes individuals truly happy and what they choose is unthinkable in neoclassical decision theory. As Gul and Pesendorfer (2008) in the debate about the use (or not use) of non-choice data put it, in "the standard approach, the term utility maximization and choice are synonymous". In other words, what an individual is observed to do is, by construction, what maximizes his utility. Second, the use of non-choice data is challenging for some economists. While using measures of subjective well-being or other measures based on physiological data or on questionnaire responses is standard in psychology, this is traditionally not the case in economics.

To illustrate the process economics is going through at the moment by integrating psychological ideas into mainstream analyses, it might be useful to note that public economics is for economics what clinical psychology is to psychology. In the former, a prominent line of research tries to identify market failures. When a market failure is present in an economy, total production or welfare can be increased by removing the market failure. This is like clinical psychology where some mental disorder is to be identified such that subjective well-being of a person can be improved once the disorder has been removed. Economics is now in the process of learning that "market failures" also exist within individuals, i.e. that choice and utility maximization is not necessarily the same.

\section{- Happiness research}

There is another group of economists that freely accept utility as a hedonic concept that measures subjectively experienced emotions: the happiness researchers. Economists working in this field ask whether average happiness ${ }^{28}$ in society rises over time and found (Easterlin, 1974) that it does not, even when countries become richer. This was dubbed the Easterlin paradox (see also Easterlin, 2001 and Stevenson and Wolfers, 2008). Economists also ask whether unemployed workers are more or less happy than employed workers. ${ }^{29}$ Building on multivariate regression analysis, they find a lot of evidence (Clark and Oswald, 1994, Di Tella, MacCulloch and Oswald, 2001, Ohtake, 2012) that unemployed workers report lower happiness values than employed workers, even when the differences in income and other socio-economic factors are taken into account. This suggests that unemployed workers would rather like to work and that at least a part of their current status is due to factors outside of their choice. ${ }^{30}$ Frey and Stutzer (2002) ask what economists can learn from happiness research. They make a strong point that subjective well-being is a good empirical proxy for utility and they argue that empirical happiness measures often provide information about desirability of e.g. economic policies that otherwise cannot be obtained.

\footnotetext{
${ }^{27}$ This formal sketch is not from the original paper. According to Peter Wakker, these equations represent a "plausible way" towards a formalization of their ideas.

${ }^{28}$ Measures used are measures of subjective well-being borrowed from earlier work by psychologists. See Diener et al (1999) for a classic survey and Clark et al. (2008) for a more recent application to economic issues.

${ }^{29}$ The average economist might be inclinced to say that unemployed workers are responsible for being unemployed. In the extreme, one might argue that it is a choice and they therefore must prefer being unemployed.

${ }^{30}$ The dynamic analysis by Clark, Diener, Georgellis and Lucas (2008) shows that the negative impact of unemployment on subjective-well being persists for at least 4 to 5 years.
} 
Conceptually speaking, the economic happiness literature is relatively atheoretic. ${ }^{31}$ Some inspiration for theory building would also come from Benjamin et al. (2012). According to their analysis of questionnaire answers, choices are determined by expected subjective wellbeing but also by "sense of purpose", "family happiness" or "social status". Overall, the happiness literature clearly views utility as being measurable by responses to questionnaires. In this sense, the happiness literature also embraces a hedonic view of utility.

\subsection{Envy, fairness, compassion and altruism}

There is a huge and very active literature on fairness (see e.g. Rabin, 1993, or Fehr and Schmidt, 1999). It is related or grew out of analyses of altruism (Becker, 1976). Altruism and envy in the simplest Becker-type structure can most simply be captured by utility that does not only depend on own consumption but also in consumption of others. If we denote utility of individual $A$ by $u^{A}$, then her utility would be given by

$$
u^{A}=u\left(c^{A}, c^{B}\right)
$$

where $u($.$) is the utility function and c^{A}$ is consumption of $A$ and $c^{B}$ is consumption of an individual $B$ (which could also stand for a large group of individuals). The function $u$ would rise in both arguments such that one could meaningfully talk about altruism of individual $A$ with respect to individual $B$. If utility $u$ rises in $c^{A}$ but falls in $c^{B}$, one could talk about envy of individual $A$ with respect to individual (or group) $B$.

The formulations of fairness in Rabin and in Fehr and Schmidt are theoretically more elaborated. They build on beliefs in the case of Rabin (see below for more background on belief-based emotions) and on inequity measures (like e.g. $c^{A}-c^{B}$ ) as arguments in the utility function in the case of Fehr and Schmidt.

If we conjecture that the basis of fairness or altruism is formed by some feeling of compassion, this literature could teach us a lot about the effects of feelings on behaviour. It seems fair to argue, however, that analyses of altruism and fairness are not in the first place about trying to understand the underlying feelings but more about the effects of altruism and fairness.

The same seems to be true for the literature on reciprocity. The survey by Sobel (2005) inquires into the nature of reciprocal behaviour. It could be of an intrinsic nature (the individual likes reciprocal behaviour per se) or it could be instrumental (the individual behaves reciprocal as s/he expects a return). Here as well, intrinsic reciprocal behaviour is probably strongly related to feelings about another person. But this survey also does not discuss feelings explicitly.

\section{$3 \quad$ Emotion analyses in economics}

This section represents the main part of this survey. We now look at how emotions are taken into account in economic analyses. Looking at theoretical constructs of emotions in economics, it turned out to be useful to classify economic analyses into four groups: Models with ex-ante emotions, models with immediate emotions and models with ex-post emotions. The fourth group includes models where emotions are modeled by so-called beliefs (where the latter term will be defined further below). In some (very rough) chronological order of when these analyses

\footnotetext{
${ }^{31}$ An outstanding exception and a further example for a hedonic interpretation of utility functions is Rayo and Becker (2007). They conceptionalize the utility function of an individual as expected happines from a certain choice. Their objective is not so much, however, to link empirical measures of happiness with theoretical concepts. They rather want to understand how evolution determines which type of happiness function is selected. Their analysis nevertheless presents interesting findings for the happiness literature: They can explain, inter alia, why happiness reverts to its long-run mean.
} 
where published, we start with ex-post emotions, then turn to immediate emotions and to ex-ante emotions to conclude with belief-based emotions.

\subsection{Ex-post emotions}

The origin of the ex-ante/ immediate/ ex-post structure comes from the fact that emotions in economics are often portrayed to result from some source of uncertainty. To take the example of an ex-post emotion, such an emotion would occur after some uncertainty has resolved. If an individual expects sunshine during holidays and it effectively rains most of the time, the uncertainty (hours of sun) had a bad realization (few hours of sun) and the individual experiences an emotion (here disappointment) ex-post, i.e. after the event, once he learns about the realization of the uncertainty.

There are at least four types of emotions that can be used to illustrate how economists understand ex-post emotions. Regret and rejoicing on the one hand and disappointment and elation on the other.

\subsubsection{Regret and rejoicing}

The fundamental aspect of the decision framework of Loomes and Sugden (1982) consists in the assumption that individuals compare the outcome of their choices to an alternative. ${ }^{32}$ Experienced utility of the individual resulting from a choice does not only include utility from the choice per se (which would be standard neoclassical economics) but also regret or rejoicing relative to the alternative. To make an example, imagine an individual can spend holidays in Italy (option 1) or in France (option 2). If she decides to go to Italy but there is more sun in France (which is the alternative), she would regret the choice. If there is more sun in Italy than in France, she would rejoice.

To formulate their idea a bit more precisely, assume the weather in Italy and France can be rainy, cloudy or sunny. The world can therefore be in $3 \times 3=9$ states and we denote these states by $j$.

\begin{tabular}{r|rrr} 
Italy $\backslash$ France & rainy & cloudy & sunny \\
\cline { 2 - 4 } rainy & 1 & 2 & 3 \\
cloudy & 4 & 5 & 6 \\
sunny & 7 & 8 & 9 \\
\cline { 2 - 4 }
\end{tabular}

Figure 1 The states $j$ of the world with Italian weather in the left column and French weather in the first row

Simplifying their approach as much as possible without loosing the essential points, utility of the individual when having chosen option 1 is given by

$$
u\left(c_{1 j}, c_{2 j}\right)=c_{1 j}+R\left(c_{1 j}-c_{2 j}\right),
$$

where $c_{1 j}$ is utility from the choice of option 1 in state $j, c_{2 j}$ is utility from the alternative choice 2 in state $j$ and $R($.$) measures regret or rejoicing. It would make sense to assume that$ there is neither regret or rejoicing $(R()=$.0 ) for states 1,5 and 9 (see fig. 1 ), rejoicing for 4,7 and 8 and regret for 2,3 and 6 .

When the decision about where to go on holiday is to be made, the state $j$ of the world is unknown. The individual therefore bases her decision on expected utility from both options.

\footnotetext{
${ }^{32}$ Bell $(1982,1985)$ independently developed related work. See Bleichrodt and Wakker (2015) for a detailed appraisal of 30 years of regret theory.
} 
In case of option 1 , expected utility $U_{1,2}$ is given by the sum over utilities in a given state of the world weighted by the probability $p_{j}$ that this state will actually realize,

$$
U_{1,2}=\Sigma_{j=1}^{9} p_{j} u\left(c_{1 j}, c_{2 j}\right) .
$$

Expected utility $U_{2,1}$ from option 2 is then expressed in perfect analogy. When considering going to France, the alternative is Italy (option 1). Utility in state $j$ of the world when having chosen option 2 is

$$
u\left(c_{2 j}, c_{1 j}\right)=c_{2 j}+R\left(c_{2 j}-c_{1 j}\right) .
$$

Here, there would be regret (for states 4, 7,8) or rejoicing (in states 2, 3,6) in exactly the opposite way as described above for the choice of Italy. Expected utility is then given by

$$
U_{2,1}=\Sigma_{j=1}^{9} p_{j} u\left(c_{2 j}, c_{1 j}\right) .
$$

It is interesting to note that even though individuals are assumed to maximize expected utility, this is not an example of expected utility theory as defined in (1). Utility here depends not only on the consequence of the choice $c_{i j}$ but also on the hypothetical alternative choice.

When the individual makes a decision where to spend holidays, this decision is then simply based on both expected utilities. Obviously, an individual will go to Italy, i.e. prefers choice 1 to choice 2 whenever expected utility in Italy is larger than expected utility in France, i.e. whenever $U_{1,2}>U_{2,1}$.

Obviously, standard, unemotional decision making is a special case of this setup. When $R()=$.0 by assumption, holiday choices only depend on utility $c_{1 j}$ and $c_{2 j}$ from option 1 and 2 in state $j$. Individuals would not compare and would just enjoy the current weather conditions wherever they ended up spending their holidays. One can easily imagine that allowing for emotions via the function $R($.$) has a strong impact on predictions about choices. { }^{33}$

\subsubsection{Disappointment and elation}

In their subsequent study on disappointment and elation, Loomes and Sugden (1986) are also interested in decision making when the difference between the outcome of a choice and some reference point plays a role. In contrast to one specific alternative, however, the reference point is now the average utility from this choice.

Formally, the states an individual takes into account now change to \{rainy, cloudy, sunny only. Numbering these states by $k=1,2,3$, the reference point for an action 1 is

$$
\bar{c}_{1}=\Sigma_{k=1}^{3} p_{j} c_{1 j}
$$

Sticking with the example from above, $\bar{c}_{1}$ stands for average utility from weather conditions for option 1, i.e. for going to Italy. Utility once in Italy is then, corresponding to (3) above, given by

$$
u\left(c_{1 k}, \bar{c}_{1}\right)=c_{1 k}+D\left(c_{1 k}-\bar{c}_{1}\right) .
$$

In words, as above, $c_{1 k}$ is utility from the choice of option 1 (Italy) in state $k$. In addition, there is now a disappointment function $D($.$) that depends on the current situation (the state k$ ) and the reference point which is expected utility $\bar{c}_{1}$. It would probably be intuitively convincing if one assumed that there is disappointment for rainy weather, neither disappointment nor elation for cloudy weather and elation for sunny weather.

\footnotetext{
${ }^{33}$ Regret and rejoicing is used by Gollier (2016) to explain rank-dependent utility.
} 
The actual holiday choice is again based on expected utilities. Expected utility $U_{1}$ from option 1 is now

$$
U_{1}=\Sigma_{k=1}^{3} p_{k} u\left(c_{1 k}, \bar{c}_{1}\right) .
$$

Expected utility $U_{2}$ from option 2 is $U_{2}=\Sigma_{k=1}^{3} p_{k} u\left(c_{2 k}, \bar{c}_{2}\right)$ and holidays are spent in Italy if expected utility there is higher, i.e. if $U_{1}>U_{2}$.

\subsubsection{Disappointment aversion}

One emotion word does not necessarily have exactly one formal description of the underlying emotion. Quite to the contrary, one and the same emotion word - disappointment in the case we consider here - can have many different interpretations. This is not surprising, however, for at least two reasons: A word is only a word and many different interpretations are natural. Second, as discussed earlier, there are different research programmes coexisting in economics and one programme provides one view while another one takes another perspective.

An alternative interpretation of 'disappointment' to Loomes and Sugden is provided by Gul (1991, p. 669). His introduction provides an exceptionally informative presentation of different reactions to observed violations of expected utility theory. Some researchers go for descriptive approaches - like Loomes and Sugden - and suggest functional forms for utility functions that are able to explain observed behaviour. The downside of this approach is that some of these utility functions violate normative features which are central to decision theory. Other researchers follow the tradition of decision theory and preserve as many of the standard axioms as possible when constructing utility functions. The approach by Gul is an example of the later and therefore nicely contrasts the approach of Loomes and Sugden presented above.

The starting point of Gul's analysis is a situation with uncertainty like our holiday choice between Italy and France from above. Disappointment and elation is also defined relative to some reference point. While the reference point above was some average utility $\bar{c}_{1}$ and $\bar{c}_{2}$, here it is the so-called "certainty equivalent" of the uncertain choice. ${ }^{34}$ If the outcome (weather conditions) is better than this certainty equivalent, the individual is elated, if not, the individual is disappointed. ${ }^{35}$ Both approaches share the view that disappointment and elation are determined by some reference point. ${ }^{36}$

The crucial distinction lies in how utility functions that capture these emotions are constructed. While Loomes and Sugden write down a "convincing" and "intuitively plausible" form, Gul derives the utility function from various axioms which are as close as possible to axioms of expected utility theory. This is the fundamental difference in their approaches and illustrates different ways of approaching the same problem (how to describe an emotion) from two different research programmes.

The outcome of Gul's analysis is a utility function that generalizes utility functions from expected utility theory by one parameter $\beta$. This parameter implies that outcomes are not weighted by their probabilities but by some adjusted probabilities. To make a simple example, we consider a holiday decision where the weather can be either sunny or rainy. Expected utility

\footnotetext{
${ }^{34}$ The certainty equivalent $c$ of a random outcome $x$ yields the same utility $u($.$) as expected utility from the$ random outcome, $u(c)=E u(x)$.

${ }^{35}$ Routledge and Zin (2010) generalize this view and define disappointment as occuring only if the outcome is sufficiently far below the certainty equivalent. This "sufficiently far" is captured by a further parameter in their utility function.

${ }^{36}$ Reference points are of course central in Kahneman and Tversky's (1979) analysis. Endogenous reference points are constructed in Kőszegi and Rabin (2006). These papers do not analyse emotions explicitly. The role of emotions in understanding political unrest is studied by Passarelli and Tabellini (2013). The central emotion, aggrievement, results from a departure of economic policy from what an individual perceives as a fair policy.
} 
under disappointment in the Gul sense then reads

$$
U=\pi u \text { (sunny) }+(1-\pi) u \text { (rainy) }
$$

where $u$ (.) is the utility from having sunny or rainy holidays and $\pi$ is the weight the utility from having sunny holidays gets. Interestingly, this is not the probability, say $p$, of sunny holidays (as would be the case in expected utility theory) but it is a function of this probability $p$, i.e.

$$
\pi=\frac{p}{1+(1-p) \beta} \text { and } 1-\pi=\frac{(1-p)(1+\beta)}{1+(1-p) \beta}
$$

where the measure of disappointment aversion is $\beta$. When individuals are not disappointment averse $(\beta=0)$, the weight sunny holidays gets is $p$ (and $1-\pi=1-p$ ). With disappointment aversion, the weight to utility from sun falls $(\pi<p)$ and the bad outcome (rainy holidays) get a higher weight.

\subsection{Immediate emotions}

Interdisciplinary research is often plagued by equivocations. Psychologists and economists discuss zealously about a certain issue, say, at a workshop, only because they use the same words (e.g. motivation, incentives or utility) but attach different meanings and concepts to them. A dictionary psychology-economics and economics-psychology would therefore help in many of these circumstances. One entry in such a dictionary would read "Craving, strong desire, lust and greed - high marginal utility".37

\subsubsection{Craving, strong desire, lust and greed}

Consider the analysis of Laibson (2001) of consumption behaviour that is driven by habits which in turn are developed through cues. As an example, think of an individual going to the university canteen for lunch and the many advertisements he encounters e.g. for sweets ranging from candies via ice-cream to chocolate bars and much more. These cues, when encountered sufficiently often, can induce strong desires for consuming one such sweet at this very instant. Desire (for a sweet) can then simply be understood as high marginal utility (from consuming a sweet).

To see this most clearly, consider an individual which in principle enjoys fruit and sweets. Simplifying the analysis of Laibson as much as possible but still capturing the essential mechanism, this could be described by a utility function that reads ${ }^{38}$

$$
u=\left(c^{\text {sweets }}-x\right)^{\alpha}\left(c^{\text {fruit }}\right)^{1-\alpha} .
$$

Given a preference parameter $\alpha$ which satisfies $0<\alpha<1$, the presence of a cue is described by a positive value of $x$. The more intensive the cue or the more susceptible the individual is to cues, the higher marginal utility, i.e. the higher is the increase in utility resulting from an increase in consumption $c^{\text {sweets }}$ of sweets. As marginal utility increases in the cue $x$, marginal utility approaches infinity for $x$ approaching the current consumption level. This can be seen as a good technical translation of strong desire, greed or craving. ${ }^{39}$

\footnotetext{
${ }^{37}$ Marginal utility from consumption measures the increase in utility when consumption is increased by a small amount. As an example, consider an individual that consumes 5 potatoes per day. Marginal utility from consumption would then be given by the increase in utility from eating 5.01 potatoes per day. Formally, when utility from consumption $c$ is described by the function $u(c)$, marginal utility is given by the derivative of utility with respect to consumption, $d u(c) / d c$.

${ }^{38}$ Utility functions with this structure are usually called Stone-Geary utility functions. See Neary (1997) for the background.

${ }^{39}$ The feeling of 'craving' also plays a role in the economic literature on addiction. The analysis of Bernheim
} 


\subsubsection{Motivations like hunger and thirst}

The above structure for modelling desire or greed can also be used to understand drives like hunger or thirst, the latter being examples of more general visceral factors influencing decision making. Loewenstein (2000) presents are more general setup than (6) where he captures visceral factors and their influence on human decision making by state-dependent preferences. When preferences in the neoclassical sense of sect. 2.2 are contingent on a certain states of the world and the state of the world is (also) understood as describing emotions of an individual, one can easily incorporate the impact of drives on preferences and thereby on decisions and behaviour.

Consider the utility function in (6), write it as $\left(c^{\text {food }}-x\right)^{\alpha}\left(c^{\text {drink }}-y\right)^{1-\alpha}$ and understand $x$ as a measure of hunger and $y$ as a measure of thirst. Then more hunger leads to a higher marginal utility from food and more thirst to a higher marginal utility from drinks. The drive creates an emotion, economically speaking, marginal utility for a certain good goes up. Hungry people will eat and thirsty people will drink.

\subsubsection{Disgust and horror}

By simply reversing the valence of the cue $x$ in e.g. (6), one can use this framework to understand disgust or horror (i.e. the opposite of craving, strong desire, lust and greed). To make a plausible example, consider a utility function that reads $u=\left(c^{\text {cigarettes }}-x\right)^{\alpha}\left(c^{\text {food }}\right)^{1-\alpha}$ instead of (6). This describes preferences of an individual for consuming (aka smoking) a cigarette and consuming food. When the cue $x$ is sufficiently negative, an individual might actually choose not to smoke cigarettes at all. An example for negative cues are warning messages on tobacco packaging. If they are only strong enough, marginal utility from smoking becomes very small (the more $x$ approaches minus infinity, the closer marginal utility lies close to zero), which one could call disgust or even horror. This would be another entry for the dictionary economics-psychology-economics. ${ }^{40}$

\subsubsection{Stress}

Most recently, the author has developed an economic approach to understanding stress and coping (Wälde, 2015). Using an established stress model from psychology (Lazarus and Folkman, 1984, Lazarus, 1999), distinguishing stressors, appraisal processes, stress and the induced coping behaviour, he employs inter alia insights from personality psychology (especially the discussion around the 'Big 5', e.g. John et al., 2008) and modern views of coping allowing for a distinction between "automatic" processes and "controlled" processes (e.g. Connor-Smith et al., 2000 and Skinner and Zimmer-Gembeck, 2007). ${ }^{41}$

While stress, simply speaking, results from the discrepancy between demand and resources, his dynamic setup portrays the change of stress as a function of the occurrence of stressors, their appraisal and three types of coping behaviour: autonomous coping (the rate at which stress reduces by "doing nothing", i.e. by letting time go by), intentional coping (e.g. talking to a friend or doing sports) and so called "emotional outbursts" which are not fully under the control of the individual. Stressors arise (in some deterministic fashion) in the form of "daily hassles" in the spirit of Kanner et al. (1981) or more rarely (and stochastically) as described e.g. by the Social Readjustment Rating Scale (SRRS) of Holmes and Rahe (1967). Formally,

and Rangel (2004) uses 'craving' to describe a situation where a cue induces an individual to consume a good (a drug) independently of whether this is utility maximizing or not. In fact, consumption choices in the state of craving are often characterised as errors by addicts.

${ }^{40}$ The political economy of hatred is studied by Glaeser (2005).

${ }^{41}$ These coping views in turn are based on dual-process models (see Chaiken and Trope, 1999 or Strack and Deutsch, 2004). 
stress follows a stochastic differential equation where uncertainty results from the rare surprises. Coping is chosen as the solution to an optimal stopping problem where the stopping feature comes from emotional outbursts that automatically take place whenever the stress level exceeds an certain tolerance level.

\subsection{Ex-ante emotions}

The final group of emotions following ex-post and immediate emotions are emotions that occur "before the fact". An individual that needs to go to a doctor for a diagnosis, a child looking forward to her birthday or an investor considering the acquisition of a large stock of risky assets are typical examples. The examples share the feature that the outcome of the event is uncertain such that the individual can experience anticipatory emotions.

\subsubsection{Anxiety, worry, fear and suspense}

A model of ex-ante or anticipatory emotions was developed by Caplin and Leahy (2001). ${ }^{42}$ Think of an investor that faces uncertain returns. To be specific, the investor makes an investment in a period $t$ and receives the return in period $t+1$. He earns a certain wage $w_{t}$ in $t$ which he can split between consumption $c_{t}$ and the investment $s_{t}$ (which stands for savings), $w_{t}=c_{t}+s_{t}$. In period $t+1$, his consumption level amounts to $c_{t+1}=\left(1+r_{t+1}\right) s_{t}$, i.e. he consumes the savings from the previous period plus interest payments $r_{t+1} s_{t}$.

To understand the decision process of the investor, we need to describe his preferences. For simplicity, the investor lives for two periods only and values consumption and experiences anticipatory emotions. Instantaneous utility in the first period $t$ is a function $u($.$) of consumption$ $c_{t}$ and the emotion $a_{t}$. Instantaneous utility is therefore written as $u\left(c_{t}, a_{t}\right)$. In period $t+1$, the investor has the same utility function $u($.$) only that there is nothing to be anticipated (as$ life is over at the end of $t+1)$. Instantaneous utility in $t+1$ is therefore $u\left(c_{t+1}, 0\right)$.

Anticipatory emotions arise as the interest rate $r_{t+1}$ is uncertain. Caplin and Leahy specify the anticipatory emotion as anxiety. Anxiety is assumed to rises in the variance of the interest rate and falls in its mean. In other words, the more there is uncertainty, the more the investor is "worried" that the interest rate differs from its expected value. At the same time, however, when the expected value of the interest rate rises, anxiety falls. Imagine the variance is constant but some marvelous mechanism can increase the average interest rate - it seems plausible that this should make an investor less anxious about the outcome of the investment.

When we then specify a certain functional form for the utility function and anxiety, one can compute optimal investment (saving) levels $s_{t}$. Most generally speaking, optimal investment is a function of preference and personality parameters, the expected interest rate, its variance and, the new feature of this setup, of anxiety. ${ }^{43}$ Asking what the determinants of optimal investment are, we can predict (at least) two relationships. (i) The more an individual is worried about the variance of the return and the less this worry reduces in the average return, the less the individual will invest. Why? Worrying a lot about the outcomes of an investment creates a lot of negative feelings with respect to investments. The optimal reaction is therefore to reduce investments. (ii) The findings become richer when we inquire about the effect of how strongly anxiety matters relative to utility from consumption. We call an individual where anxiety matters a lot an emotional individual compared to an individual that looks more at utility from consumption. We then find that a more emotional individual will save less only if the individual worries enough. In other words, there is a dependency of the emotion effect on the

\footnotetext{
${ }^{42}$ This framework was applied and generalized inter alia by Caplin and Leahy (2004) and Köszegi (2006).

${ }^{43}$ Appendix A.3 contains an explicit example with a more precise description of some results.
} 
worry-effect. Put differently, an individual that is more emotional could save more if he does not worry too much. ${ }^{44}$

\subsubsection{Savouring and dread}

In contradiction to the general presentation above of ex-ante and ex-post emotions, anticipatory feelings do not necessarily have to be based on uncertain events. The analysis by Loewenstein (1987) presents a framework which allows to understand the effects of anticipation on optimal behaviour in a deterministic world.

- The setup

In his view, anticipation means feeling utility from future consumption already today. This moves the analysis beyond the standard economic forward-looking behaviour. To understand this, let us denote the current point in time by $t_{0}$, as shown in fig. 2 , two future points in time by $T$ and $T+L$ and any point between $t_{0}$ and $T$ by $t$. We denote points in time between $T$ and $T+L$ by $\tau$.

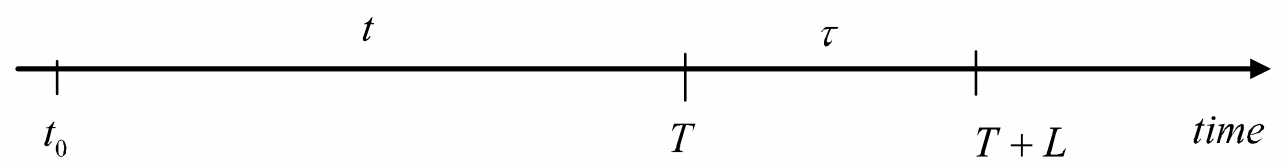

Figure 2 Timing of events

Start by considering a typical intertemporal homo oeconomicus that consumes a constant stream $c$ at each point in time $\tau$ between $T$ and $T+L$. Instantaneous utility from consuming this good is given by $u(c)$. The present value $U^{s}\left(t_{0}\right)$, where $s$ stands for 'standard', of this consumption stream at the current point in time $t_{0}$ is given by

$$
U^{s}\left(t_{0}\right)=\int_{T}^{T+L} e^{-r\left[\tau-t_{0}\right]} u(c) d \tau .
$$

In words, the present value for utility from consumption at $\tau$ for the starting point 0 is $e^{-r \tau} u(c)$ when we use a constant interest rate $r$ to discount utility. When we sum up over all instantaneous utilities (that occur between $T$ and $T+L$ only), we obtain the integral on the right hand side. This is the standard objective function, which we already saw in (2), which is used in zillions of intertemporal models of utility maximization.

Now we add utility from anticipation. For any point in time $t_{0} \leq t \leq T$, i.e. at any time before consumption begins at $T$, the individual derives instantaneous utility from anticipating the consumption stream between $T$ and $T+L$. This utility is given by

$$
u^{A}(t)=\int_{T}^{T+L} e^{-\delta[\tau-t]} u(c) d \tau .
$$

As for the standard intertemporal utility function in (7), the present value of anticipation is obtained by discounting $u(c)$. For anticipation, the discount rate is $\delta$. When we sum up over the entire consumption stream, we obtain the present value of anticipation of the entire future consumption stream. We denote this utility from anticipation by $u^{A}(t)$. As our individual

\footnotetext{
${ }^{44}$ Again, appendix A.3 contains the details of this result.
} 
experiences this anticipation at each moment in time $t$ between $t_{0}$ and $T$, we obtain the present value $U^{A}$ from anticipation by integrating over the entire period from $t_{0}$ to $T$. Hence, we get

$$
U^{A}\left(t_{0}\right)=\int_{t_{0}}^{T} e^{-r\left[t-t_{0}\right]} u^{A}(t) d t .
$$

While a standard intertemporal utility maximization problem would start with (7) as objective function to be maximized, the utility function of Loewenstein with anticipation reads

$$
U\left(t_{0}\right)=U^{s}\left(t_{0}\right)+\alpha U^{A}\left(t_{0}\right) .
$$

The parameter $\alpha$ captures "imaginability" or "vividness" (Loewenstein, 1987, p. 670) of a future event. The discount rate $\delta$ in (8) can be seen as capturing the degree of preoccupation of an individual with future events.

- Delaying events or bringing them forward

The setup provides conditions under which an individual wants to delay or bring forward a certain event. The remarkable aspect is that allowing for savouring (there is a desirable event in the future, $u(c)>0$ ), it can be optimal for the individual to delay this desirable event. Under the standard setup from (7), where the individual is simply impatient, this would never happen. The individual would choose $T$ to be equal to $t_{0}$, i.e. the individual would start the desirable event immediately. With savouring, when $\alpha$ is sufficiently large, i.e. when the individual enjoys the present value from anticipation in (9) a lot, the individual may want to move the point in time $T$ when the future event starts into the future. The individual would also delay when $\delta$ from (8) is very small: the instantaneous utility from anticipation is very strong.

When there is an unpleasant event waiting in the future, $u^{A}(t)$ would stand for dread as $u(c)$ would be negative. The standard setup from (7) would then imply deferring as much as possible. A negative event sufficiently far in the future has a present value of zero when $t$ in the discount function $e^{-r\left[t-t_{0}\right]}$ becomes sufficiently large. When anticipation plays a role as well, optimal choice of $T$ can reverse: the individual may choose $T$ to be today to bring forward this dreadful event.

\subsubsection{Fear created by terrorism}

Becker and Rubinstein (2011) analyse the effect of terrorism on fear of individuals and the effect this fear has on their behaviour. In their analysis, fear $F($.$) is a function of various$ determinants, written analytically as

$$
F(\tau, m)=(1-E) f(\tau, m) x
$$

Starting from the back of this equation, fear depends on consumption $x$ of some terror-related goods. These goods can be e.g. airline or bus services or any other services which are subject to terrorist attacks. Fear is then determined by the degree of terrorism $\tau$ and by media coverage $m$. When there is no terrorism, there is no fear, i.e. for $\tau=0$, it holds that $f(0, m)=0$. By contrast, for a given level of terrorism, fear rises in media coverage, i.e. the derivative of $f($. with respect to $m$ is positive. The individual can control one's fear which implies that $E=1$ and fear vanishes. If there is no fear-regulation, $E=0$. Fear-regulation is costly and reduces disposable income for consumption purposes.

Psychologically speaking, the stimulus that is at the origin of the fear is the consumption of a good $x$. If an individual does not fly by plane and does not use bus services, i.e. if $x=0$, the stimulus is absent and there is no fear. This stimulus is appraised for one's personal objectives 
and this appraisal is described by $f(\tau, m)$. When there is no terrorism $(\tau=0$ and $f(0, m)=0)$, there is no fear. For a given level $\tau$ of terrorism, the appraisal becomes more intense and fear rises, the higher salience of terrorism through media coverage $m$. Given the "gross" feeling of fear $f(\tau, m) x$, the individual can then invest in fear-regulation by choosing $E$. The "net" feeling of fear is then $(1-E) f(\tau, m) x .^{45}$

The authors use this formalization of fear to relate it to individual perception. The higher fear, the lower the subjective belief an individual holds for surviving a terrorist attack. This subjective probability is also perceived to fall in the degree of terrorism and the consumption level $x$ of the terror-related good. Letting individuals maximize expected utility with subjective beliefs serving as probabilities for certain outcomes, fear has an impact on decision making of the individual. ${ }^{46}$

\subsection{Belief-based emotions}

Emotions as portrayed in the models above were either the ex-post outcome of some uncertain event (e.g. disappointment and elation), the ex-ante evaluation of some future uncertain event (anxiety and positive anticipation), driven by some cues (craving or disgust) or modelled as the outcome of some appraisal process of a certain event (stress). Many of these approaches are relatively strongly related to psychological thinking.

We will now get to know an approach whose ties to psychological theories of emotions at first sight appear less strong, at least for some applications. On the other hand, the mathematical "machinery" behind this approach is so very well developed that one can base emotion analyses on very solid grounds and use many existing results. This approach views emotions as the result of beliefs.

Beliefs come in several guises in economics: They are known from Bayesian learning where a belief is a subjective probability. ${ }^{47}$ They are also known from models with just one or several relatively independent decision makers. Finally, and this is maybe the field where belief-based emotions are most popular, they are used in game-theoretic frameworks.

Belief-based emotions in games were introduced by Geanakoplos, Pierce and Stacchetti (1989) in their paper entitled "psychological game theory" which will be presented in the next section. Once we have understood this general framework, we will look at an application that analyses how guilt (Dufwenberg, 2002) can arise and how this affects behaviour in marriage. A single-actor perspective is taken by Compte and Postlewaite (2004) in their analysis of selfconfidence. We conclude this section by offering a short impression of the area where beliefs are probably the most widely used but where, unfortunately, hardly any emotion analysis is undertaken: Bayesian learning.

\subsubsection{Psychological game theory}

One of the most important concepts to analyse and to understand social interactions with few participants is game theory going back to von Neumann and Morgenstern (1944). The outcome of a game as understood by game theory is usually a 'payoff' for the players. As elsewhere in economics, payoffs are understood as material payoffs like money or so-and-so many units of

\footnotetext{
${ }^{45}$ The terms gross and net fear are inspired by gross and net wage, i.e. before and after taxation.

${ }^{46}$ Ex-ante emotions as treated in this subsection can of course arise jointly with ex-post emotions. Gollier and Muermann (2010) use such a setup and allow a decision maker to choose the optimal degree of optimism to balance the two sources of emotions.

${ }^{47}$ One can argue that beliefs are not very special as compared to standard decision making under uncertainty where agents also need to form beliefs. One big difference lies in the fact that beliefs as covered in this section are subjective probabilities whereas beliefs in more standard models (which in economics would then not be called beliefs) are objective probabilities.
} 
a consumption good. Geanakoplos, Pierce and Stacchetti (1989) coin the term "psychological game theory" for games where payoffs can also be functions of beliefs. ${ }^{48}$ A belief is a subjective probability distribution a player attaches to the unknown probability with which another player will behave in a certain way. To make an example, if player 1 behaves in a, say, timid fashion with a certain probability and in a bold fashion otherwise, player 2 can hold a certain belief about this probability of player 1 acting timid.

Assuming that individuals enjoy not only material payoffs but also care about what others believe, psychological game theory opens the door to applying game theory also to setups where emotions play a role. Geanakoplos et al. (1989) in fact argue that "psychological games ... allow one to model belief-dependent emotions such as anger or surprise" (p. 60). The unifying feature of models in the tradition of 'psychological game theory' is therefore that an emotion is the result of a belief. To understand these ideas better, we now look at the simplest psychological game that was presented in Geanakoplos et al (1989, p. 66-67), the 'bravery game'.

- The setup

Imagine there are two individuals, called player 1 and player 2. Player 1 must take a decision and is concerned what his friend (player 2) thinks about him. Player 1 can either act in a bold or in a timid way. Player 2 does not make any decision. Player 1 can choose pure strategies, i.e. can choose to act bold or to act timid, or he can attach a probability $p$ to being bold when playing mixed strategies. In the latter case, it is not the strategy which is chosen optimally but the probability (here $p$ ) with which a strategy is played.

The payoffs to both players are shown in figure 3. If player 1 acts bold, the payoff to him is $2-\tilde{q}$ units of utility. This payoff consists of a material payoff ( 2 units of money or of a consumption good) plus a non-material (emotional) payoff $\tilde{q}$ to be discussed in a moment. The payoff to player 2 is $2+2 q$, i.e. a material payoff of 2 and a non-material payoff of $q$ also to be discussed below. The payoffs in case player 1 acts timid are $3-3 \tilde{q}$ for player 1 and $1-q$ for player 2 .
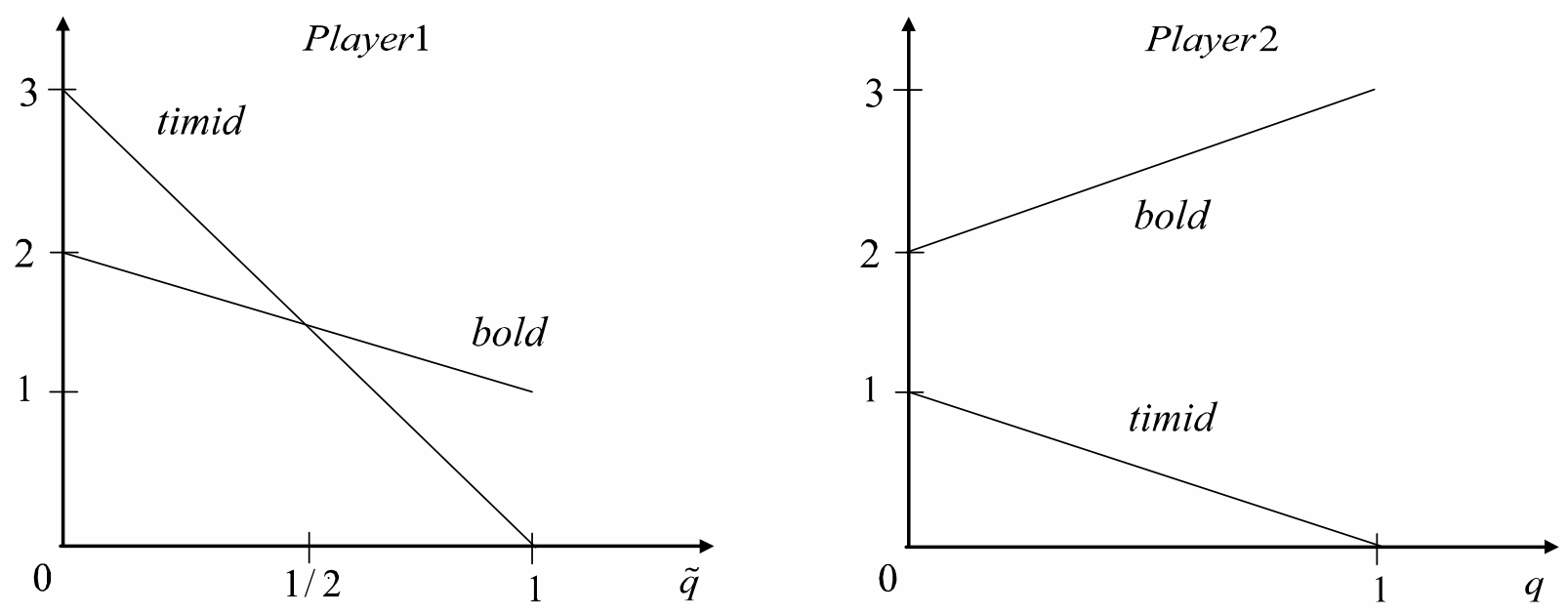

Figure 3 The bravery game (Geanakoplos et al., 1989, figure 2)

To provide some background, imagine for a moment, this is not a psychological game. Then players would care only about their material payoffs which for player 1 would be 2 for acting bold and 3 for acting timid. When player 1 cares only about own payoff (i.e. he is the typical

\footnotetext{
${ }^{48}$ This is related to "information-dependent games" of Gilboa and Schmeidler (1988), who, however, do not analyse emotions. Akerlof and Dickens (1982) also used belief-dependent emotions. See further below for a short discussion. A strategic approach to emotions is also used by Winter et al. (2016).
} 
self-interested homo oeconomicus) and he plays pure strategies, he would act timid as this yields a higher payoff. The material payoff to player 2 would then be 1 . When player 1 plays mixed strategies and attaches a probability $p$ to playing bold, then the optimal choice of $p$ would be zero. He would play timid with probability one. Obviously, his payoff would be 3 and the payoff for player 2 would be 1 - pure and mixed strategies lead to the same outcome.

The analysis becomes interesting when we allow for non-material payoffs. We are then analysing a psychological game. The starting point is that player 2, for whatever reasons, prefers to think of player 1 (his friend, partner, boss, leader of his sports team etc.) as being bold. This belief is described in relation to the probability $p$ that player 1 actually plays bold. Formally, it is assumed that player 2 does not know this probability $p$ and therefore needs to attach a subjective probability distribution to the true but unknown value of $p .{ }^{49}$ The belief of player 2 about the probability with which player 1 plays bold is then denoted by $q$ and is simply the expected value of $p$ (given the subjective distribution player 1 attaches to the probability $p)$.

The non-material payoff for player 2 when player 1 plays bold then consists in $2 q$, i.e. he is rewarded for believing in the boldness of player 1 when player 1 actually behaves in this way. This can be understood as a positive feeling from having judged player 1 in a correct way, similar to elation or at least relief. This is the first belief-dependent emotion. By contrast, when player 1 acts timid, player 2 is punished for his belief that player 1 is bold, his non-material payoff is $-q$. Player 2 would be disappointed; this is the second emotion that can occur for player 2 .

What are then the non-material payoffs of player 1? It is assumed that player 1 is concerned about what player 1 thinks about him. Hence, player 1's payoffs also depend on what he believes about what player 2 believes. As player 1 does not know the beliefs of player 2 (given the same arguments as for player 2), he needs to work with a subjective probability distribution for $q$. Player 1's average belief about the belief of player two is then denoted by $\tilde{q}$. Concerning what player 2 values, it is assumed that he wants to exceed the expectations of player 2 . He does not want to disappoint player 1 and therefore enjoys being more bold than player 2 believes. The payoffs of player 1 therefore fall in $\tilde{q} .^{50}$

\section{- Optimal behaviour}

Given this setup, the question is how player 1 will behave. The simple answer is: he will choose timid, if the payoff from timid, $3-3 \tilde{q}$, exceeds the payoff from acting bold, $2-\tilde{q}$. These payoffs obviously depend on player 1's belief $\tilde{q}$ about how strongly player 2 beliefs he is bold as shown in figure 4 . If $\tilde{q}$ is very low, player 1 plays timid, when $\tilde{q}$ is larger than $1 / 2$ (at which point player 1 is indifferent between the two strategies), he will play bold. So the true question is, what the belief $\tilde{q}$ of player 1 is.

\footnotetext{
${ }^{49}$ This is a fascinating concept, which is also known e.g. from Bayesian learning (see sect. 3.4.4), which could be called "double uncertainty". The starting point is some random variable (the behaviour of player 1). The probability distribution of this random variable is not known which implies that the probabilities of the individual realizations become uncertain as well.

${ }^{50}$ Alternative assumptions are of course possible. If one assumed that player 1 wants to confirm the belief of player 2 , then payoffs of player 1 would rise in $\tilde{q}$ when acting bold and would fall in $\tilde{q}$ when acting timid. In what follows we stick to the assumptions in the original paper. My thanks go to Ennio Stacchetti for discussions of this point.
} 

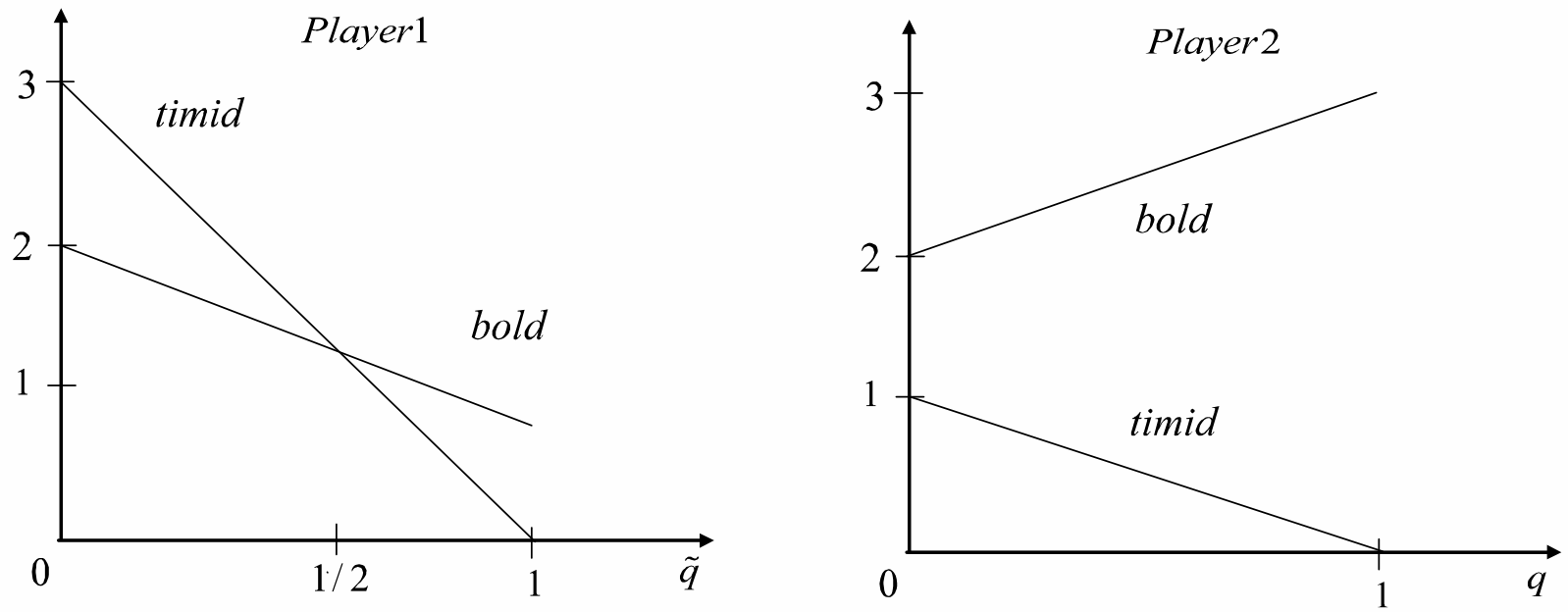

Figure 4 Payoffs as a function the behaviour of player 1 and of beliefs

To understand this, and to understand the determinants of emotions and their strength, we need to understand certain axioms that are usually imposed on equilibrium behaviour. Without these axioms, beliefs $q$ and $\tilde{q}$ could not be determined and no prediction (or too many of those) of the behaviour of player 1 would be possible. The axioms for equilibrium behaviour are (i) that beliefs are consistent with behaviour: an outcome would not be called an equilibrium if e.g. player two believes that player 1 is bold but player 1 acts timid. We also impose (ii) that beliefs are shared among players and that beliefs correspond to the actual probability with which player 1 plays bold, $p=q=\tilde{q}^{51}$

- Behavioural predictions

We have seen that there is a unique prediction, i.e. a unique equilibrium in the absence of non-material payoffs: player 1 plays timid. With beliefs, three equilibria can occur. Either player 1 plays bold with probability $p=1$, in which case player 2 believes that player 1 is bold, $q=1$, and player 1 believes that player 2 believes that he is bold, $\tilde{q}=1$. The payoffs for player 1 are $2-\tilde{q}=1$ in case of acting bold and $3-3 \tilde{q}=0$ in case of playing timid. As $1>0$, and as acting confirms beliefs, playing bold is actually an equilibrium.

In the second equilibrium the probability to play bold is $p=0$ and so are beliefs. Payoffs for player 1 are $2-\tilde{q}=2$ and $3-3 \tilde{q}=3$. As 3 exceeds 2 , player 1 acts timid, his action confirms beliefs and beliefs and the probability $p$ coincide, this is another equilibrium.

After having seen two equilibria with pure strategies, ${ }^{52}$ we now turn to mixed strategies. An obvious candidate from figure 4 is playing bold with probability $p=0.5$. This would imply that beliefs are 0.5 as well. Player 1 is then in fact indifferent between both strategies as payoffs are $2-\tilde{q}=1.5$ and $3-3 \tilde{q}=1.5$. Behaviour would again confirm beliefs and a third equilibrium is established.

- What do we learn about emotions? The appraisal interpretation

As Geanakoplos et al. (1989) put it in their abstract, they describe belief-dependent emotions in their psychological games. To add another entry into the to-be-written dictionary

\footnotetext{
${ }^{51}$ As any definition or any assumption, an axiom can only be "tested" by a person's intuition. These are standard axioms widely used in game theory. Other intuitions would imply different axioms which in turn would imply different behavioural predictions.

${ }^{52}$ One can alternatively describe these two pure strategies as (degenerate) mixed strategies with probabilities 1 and 0 , respectively.
} 
economics-psychology-economics, we will now provide an interpretation of the above setup in terms of appraisal theory (e.g. Scherer et al., 2001). We will identify a stimulus, an appraisal of the stimulus and the resulting emotion. We also identify how the emotion translates into payoffs (utility) of the actor. We are best able to do this when we write the payoffs a bit more generally than in fig. 3 .

We start with the case of acting timid. We write payoffs as $3+f(\tilde{q}$, timid $)$ and $1+g(q$, timid $)$ (instead of $3-3 \tilde{q}$ and $1-q$ ). Function $f$ describes emotions in units of payoffs that arise from the belief $\tilde{q}$ of player 1 and from the strategy $s$ chosen by player $1 .{ }^{53}$ We keep material payoffs as they are and slightly generalize non-material payoffs. We start with player 2 as he is easier to understand. The stimulus of player 2 is the observation that player 1 acts bold. He evaluates this stimulus choosing as evaluation criterion his belief about the character of player 1 . As player 2 believes player 1 to be bold, the evaluation is negative. What is more, the valence of the evaluation becomes smaller, the more strongly he believed that player 1 is bold. We write this valence of the evaluation of the stimulus as $-\phi_{1} q$ where $\phi_{1}$ captures the intensity of an evaluation and the minus sign captures the negative valence given the stimulus. This evaluation is then also the negative feeling. To express the negative feeling in units of payoffs, we multiply it by a conversion parameter $\chi$ such that we end up with $g(q$, timid $)=-\chi \phi_{1} q$. To simplify notation, we can set $\chi \phi_{1}$ equal to 1 such that we end up with the same total payoff as in fig. 3.

Looking at player 1, the stimulus is his own action. As he acts timid and evaluates this along the lines of his intention to exceed beliefs of player 2, the evaluation is negative. The intensity of his evaluation is described by $\phi_{2} \tilde{q}$, i.e. it depends on how strongly player 2 beliefs that player 1 believes him to be bold. The more player 2 believed him to be bold, the more negative his feelings $-\phi_{2} \tilde{q}$ are. Translating this again into units of payoffs, we get $f(\tilde{q}$, timid $)=-\chi \phi_{2} \tilde{q}$ where we used the same conversion parameter $\chi$ as for player 2 . The intensity of the evaluation $\phi_{2}$ can however differ from the intensity of player 2 . To obtain again the same expression as in fig. 3, we set $\chi \phi_{2}=3 .^{54}$

For the case of acting bold, we rewrite payoffs, in a similar way as in the timid case, as $2+f(\tilde{q}$, bold) and $2+g(q$, bold) (instead of $2-\tilde{q}$ and $2+2 q)$. The stimulus of player 2 is behaviour of player 1. Given the expectation (i.e. the belief) of player 1 , the emotion $g$ ( $q$, bold) of player 2 is positive as behaviour of player 1 confirms his belief. As the relief is the stronger, the more player 2 believes that player 1 is bold, the positive emotion rises in $q$ and the intensity of the feeling is captured by $\phi_{2} q$. In utility terms, we get $g(q$, bold $)=\chi \phi_{2} q$. The expression from fig. 3 holds for $\chi \phi_{2}=2$.

When player 1 acts bold, his stimulus is again his own behaviour. He appraises this action relative to his attitude of wanting to exceed the beliefs of player 2. As player 2 wants player 1 to be bold, acting bold would indeed exceed the beliefs of player 2. This "overfulfillment" of expectations turns out to be the lower, however, the higher the belief $\tilde{q}$ of player 2 . For this reason, $f(\tilde{q}$, bold) is negative. When we make the feeling a function of the belief and add the by now well-understood intensity and utility parameters, we get $f(\tilde{q}$, bold $)=-\chi \phi_{2} \tilde{q}$. Normalizing $\chi \phi_{2}$ to one, we get $f(\tilde{q}$, bold $)=-\tilde{q}$.

\subsubsection{Trust and guilt}

Subsequent analyses building on this general framework of psychological games provide many examples of very illuminating views about emotions and their implications for behaviour. We now turn to one such application.

\footnotetext{
${ }^{53}$ This description of feelings as a function of the strategy $s$ chosen by player 1 is a tiny generalization as compared to the original setup of Geanakoplos et al. (1989). It helps in understand the nature of emotions.

${ }^{54}$ It is probably fair to say that most economists do not have a concept of stimulus-appraisal-feeling in mind when writing down equations. But one can very easily given such a psychological interpretation.
} 
The feeling of guilt as the result of a (potential) divorce was studied by Dufwenberg (2002). The background for the modelling of payoffs (here: the feeling of guilt) are "findings in social psychology based on autobiographical accounts by Baumeister et al. (1993) < that > document that a person who rejects a relationship partner often suffers from guilt. Baumeister et al. (1994, 1995, p. 174) report that: "the prototypical cause of guilt is inflicting harm or distress on a relationship partner"" (quote from Dufwenberg, 2002, p. 58). While there are many extensions and related applications of Dufwenberg (2002), ${ }^{55}$ we stick to this first model here as it presents the basic idea of modelling guilt (and also trust) in a very clear way.

Following the tradition of psychological game theory, guilt is modeled as a belief. To understand this, we start from the fact of life (at least in the model) that there is a certain probability (call it $\tau$ ) that the husband never divorces and that there is the complementary probability $1-\tau$ that he in fact divorces. The first belief (and thereby the first emotion in this situation) is the belief of the wife about the probability of not-divorcing. This belief is necessary as the wife does not know the true probabilities ( $\tau$ in this case) and therefore forms a certain subjective belief about this probability. We call the wife's belief $\tau^{\prime}$ (which formally speaking is the mean of $\tau$ ). This belief can be called trust.

Guilt then results, in the case of a divorce (which is the stimulus in the sense of appraisal theory as discussed above), as a function of the husband's belief $\tau^{\prime \prime}$ how much his wife trusted him (this is the appraisal dimension of the husband) and a parameter measuring the sensitivity of the husbands utility from guilt. Slightly more generally than in the original paper, utility $u_{d}^{h}$ of the husband $h$ in case of divorce $d$ would read

$$
u_{d}^{h}=4-\chi \phi \tau^{\prime \prime}
$$

where $\phi \tau^{\prime \prime}$ is the feeling of guilt that depends on a parameter $\phi>0$ and the belief $\tau^{\prime \prime}$. Guilt $\phi \tau^{\prime \prime}$ is the higher, the higher trust of the wife. Intuitively speaking, if the husband believes that the wife trusts him strongly that he will not divorce, his feeling of guilt is very strong when he in fact divorces. The parameter $-\chi$ translates the feeling into utility units. Disutility $-\chi \phi \tau^{\prime \prime}$ from guilt can be compared with and added to some material payoff 4 (e.g. income of the husband after divorce). Merging $\chi \phi$ to some parameter $\gamma$ would give the formulation in the paper by Dufwenberg.

\section{- Divorce or not?}

The intention of the paper is to understand joint decision making in marriage. In a first stage, the wife makes the decision whether to support the husband in his professional career or not. Once this decision has been made, the husband decides whether to stay with the wife and share income or whether to divorce, not share the income and feel guilty. Various behaviours can occur in equilibrium. Interestingly, they strongly depend on how guilty the husband feels when opting for a divorce. A husband with strong feelings of guilt (a sufficiently high $\gamma$ ) will obtain support from his wife and not divorce. An emotion-free husband (pure homo oeconomicus with $\gamma=0$ ) would not receive support for his professional plans (and not divorce either). Strong feelings of guilt are therefore desirable for both partners as they make sure that divorce does not happen and that a professional career is possible.

\footnotetext{
${ }^{55}$ Charness and Dufwenberg (2006) use a framework with guilt, guilt aversion and communication to study the effect of communication on trust and cooperation in an experiment. Battigalli and Dufwenberg (2009) introduce two concepts of guilt aversion: "Simple guilt" results from the fact that "a player cares about the extent to which he lets another player down". This is as in Dufwenberg (2002) as discussed in the text. The second concept is "guilt from blame" which occurs if an individual does not like to be blamed. Charness and Dufwenberg (2011) provide further evidence from a guilt-related experiment.
} 


\subsubsection{Self-confidence}

There are also analyses where beliefs form the basis of emotions but where there are no strategic interactions. These analyses are maybe even more suitable to understand the effect of emotions on behaviour as the more involved equilibrium concepts of game theory are absent. One such example for belief-based emotions is self-confidence, to which we now turn. ${ }^{56}$

Consider an individual that needs to decide whether to undertake some risky activity, say an investment project. The probability of success depends on some project-related criteria (e.g. technical properties of the project) and on the person who runs the project. The influence of the person could be objective (how good do the skills of this person fit for the task) but it could also be more subjective (how much do the customers believe that the person fits for the task). Compte and Postlewaite (2004) focus on the latter and allow for a feeling of confidence to play a role in the probability of success for a project. They see self-confidence as an example for "emotions that affect performance" (p. 1536). Confidence describes "feelings of assuredness and lack of anxiety" (p. 1539).

More in detail, let $\rho$ denote the (objective) probability of success of a project. This probability is the product of confidence $0<\kappa \leq 1$ of the individual and the project-related component $\rho_{0}$ of the success probability. Making confidence a function of the frequency $\varphi$ of past success, the probability of success becomes a function of the frequency of past success,

$$
\rho(\varphi)=\kappa(\varphi) \rho_{0} .
$$

Going beyond the description of Compte and Postlewaite, one can understand the objective probability of success $\rho$ as the product of the probabilities of two (independent) events. As an example of a project, consider "going to the office by bike". Its probability depends on the probability $\rho_{0}$ that the bike is technically well-maintained such that it does not break down on the way to the office. The probability also depends on the probability that the person is able to go by bike (and does not end up in an accident). The frequency $\varphi$ of past successes would then be the objective measure for this individual probability while confidence $\kappa(\varphi)$ is a potentially biased measure, a subjective belief of one's true probability. When $\kappa(\varphi)>\varphi$, the individual is over-confident, an individual that is excessively anxious would be characterised by a $\kappa(\varphi)<\varphi$.

\subsubsection{Optimism and pessimism}

There is a huge literature on Bayesian learning where subjective beliefs are updated following the availability of new information (deGroot, 1970, 2004). One of the immediate questions of such a framework is then whether individuals will ever obtain enough information to learn the truth. In some of the applications of this Bayesian learning setup (e.g. in the labour market analysis of Launov and Wälde, 2013), authors talk about optimism when the initial subjective belief lies above the true value (and about pessimism in the other case).

Most of these analyses stop at this point in the sense that no emotional interpretation of beliefs (apart from casual use of the words optimism and pessimism) is provided. Yet, this standard and well-understood formal framework should turn out to be highly useful for future analyses of emotional processes. Gradual updating in this Bayesian sense has the advantage as compared to beliefs which instantaneously need to satisfy equilibrium conditions that beliefbased emotions would only slowly change. The determinants of changes of emotions would then become more transparent.

\footnotetext{
${ }^{56}$ In their analysis of cognitive disonance, Akerlof and Dickens (1982) also used belief-dependent emotions. They study workers employed in an industry where there is a certain probability that an accident occurs. These workers have a "psychic cost of fear" where fear is an increasing function of the subjective probability that an accident occurs. Optimal beliefs who trade off ex-ante benefits or emotions vs. ex-post costs or emotions are studied by Brunnermeier et al. (2007) or Gollier and Muermann (2010). These analyses are inspired by the optimal expectations framework of Brunnermeier and Parker (2005).
} 


\section{Why emotional economics is useful ...}

The final question of this survey asks why emotions enter economic analyses and whether these economic analyses have any value added for psychology.

\section{$4.1 \quad$... for economics}

Economic theory advances by taking emotions into account. This is because either emotions improve the predictive power of existing models or enlarge the theoretical apparatus at the disposal of economists (or both). In the first case, emotions serve more as a 'label' for describing certain standard economic constructs. Psychological research plays less of a role (if at all). In the second case, psychological research provides the motivation and sometimes even guides economic model building. We present examples here for both ways of theoretical progress.

\subsubsection{Improving predictive power}

From reading the introduction of Loomes and Sugden (1982), it becomes clear that they develop their theory of decision making due to the many violations of fundamental axioms of expected utility theory. These departures were documented forcefully by Kahneman and Tversky (1979) earlier (to whom Loomes and Sugden, 1982, refer and which led Kahneman and Tversky to develop their famous 'prospect theory'). The objective of Loomes and Sugden was therefore not to understand a specific emotion per se but to understand the effects of the emotion on decision making of individuals. This brought them to their decision models which are descriptively more successful in explaining observed human behaviour than standard models from expected utility theory.

The motivation for Gul (1991) is similar: Behaviour observed in experiments departs in a systematic way (giving rise to the so-called Allais paradox) from central axioms of expected utility theory (the independence axiom). Gul poses the question of how this axiom can be relaxed to account for this violation and to make predicted behaviour consistent with the Allais paradox. Whether there was an initial intention to come up with a model that describes emotions or whether a formal analysis eventually revealed a structure that could be given an intuitive interpretation by using the concept of disappointment and elation can only be answered by the author. Whatever the intention, the outcome of this analysis is a fascinatingly simple and elegant characterisation of disappointment. If things go better than some reference point, people are elated, if not, they are disappointed. More towards the motivation of Gul's paper, his theory of decision making is consistent with the Allais-paradox and therefore improves predictive power of decision models.

\subsubsection{Enlarging the theoretical apparatus}

The objective of Laibson's (2001) study lies in introducing knowledge from psychology for economic theory building. He writes that the connection between cues, the forming of habits and the implied consumption behaviour "is already discussed in the psychological literature" (p. 82). From an economic theory point of view, earlier work of Becker and Murphy (1988, 1993) have presented two distinct building blocks of Laibson's analysis - the formation of habits (in Becker and Murphy, 1988) and the link between cues and consumption (in Becker and Murphy, 1993). The analysis by Laibson combines these two building blocks to end up with a decision framework "using psychological evidence" (p. 83). Most interesting probably from a theoretical perspective is the fact that preference can change from one instant to another as a function of the cues. This clearly enlarges the set of models with which to look at individual behaviour. 
The starting point of Caplin and Leahy (2001) is the everyday observation that "We all experience feelings related to our uncertainty about the future, such as hopefulness, anxiety, and suspense" (p. 55). They acknowledge that this aspect has long been recognized by psychologists but that economists have largely neglected these aspects in decision making. ${ }^{57}$ This shortcoming in economic theory should be overcome as anticipatory emotion can cause time-inconsistent behaviour, a behaviour which is widely acknowledged in economics, psychology and elsewhere to be of high everyday relevance. They strongly base their analysis in psychological thinking and provide a brief survey of the psychological literature on anticipation. They conclude that human decisions do depend on anticipatory emotions and that humans take action to reduce anxiety. Looking at their analysis, it serves (at least) two purposes. First, it provides an explanation of time-inconsistent behaviour and in this sense the paper could be classified under "enlarging predictive power". Second, and probably more far-reaching, they provide a new framework for understanding a decision process which has so far not been available in economics.

The analysis on stress by Wälde (2015) is a further example of the strategy to import psychological knowledge into economics. In a sense, it is surprising that this did not take place earlier. The concept of stress was introduced into medical science by Selye (1936) a long time ago and has received attention in psychology at least since World War II (e.g. Lazarus and Folkman, 1984, Lazarus, 1999). Stress is also very present in everyday life: A German governmental agency issued a stress report (Baua, 2012) and health insurance companies put a special emphasis on stress in their annual report (DAK, 2014). The French government issued a report on happiness (Stiglitz, Sen and Fitoussi, 2008) and Helliwell, Layard and Sachs (2013) edited a world happiness report. Both of these reports are full of references to the concept of stress. Further, the economic world hosts a long list of stressors (new technologies, globalization, financial innovations leading to financial crises, unemployment, inequality and poverty). Yet, and this is why a transfer of knowledge from psychology to economics is needed, economics does not have a conceptual framework that would allow to study the implications of these stressors for stress and the responses of individuals to stress.

\subsubsection{Future research}

Various models from emotional economics suggest extensions or applications which bring further knowledge from psychology into economics (Rabin, 2013). As an example, the extended utility function in (6) from the section on cravings could also be used to understand James-Lange views of emotions. An stimulus implies a bodily reaction which in turn then leads to the emotion. A more elaborated version of (6) could therefore provide a more formal analysis of e.g. Damasio's somatic marker hypothesis (see e.g. Bechara and Damasio, 2005). An emotion according to their definition is "a collection of changes in body and brain states" (p. 339). Once a cue is perceived, the body reacts accordingly: there are "changes in internal milieu and viscera" or "changes in the musculoskeletal system" (p. 339). When $x$ and $y$ (and potentially further variables) represent the state of the body (and changes in these variables then the change of the state of the body), such a theory would provide an immediate and very precise link between body states and observable behaviour.

\section{$4.2 \quad$... for psychology}

Is "emotional economics", the analysis of emotions in an economic tradition, useful for advancing psychological understanding of emotions? This question is hard to answer at this point if 'advancing psychological understanding' means 'a contribution to the psychological literature'.

\footnotetext{
${ }^{57}$ They mention two to three exceptions of which one is the analysis by Loewenstein presented earlier.
} 
To work out whether economic analyses of emotions would contribute to the psychological literature would require to go into much depth into this literature and see where emotion research currently stands with respect to the various economic analyses. As the author is not sufficiently knowledgeable about psychological research to do this, only some general remarks can be made here.

\subsubsection{More determinants}

Any analysis from a different field than the standard one will include different determinants than in the standard field. In the stress model by Wälde (2015), stress is primarily the result of stressors and an appraisal process and can be reduced by coping. Given that it is an economic model, the individual is also working and receives a wage. An additional determinant of the stress level of an individual is therefore the wage of a person.

In the anxiety model by Caplin and Leahy (2001), anxiety is a function of measures of uncertain consumption via uncertain investment. As consumption also depends on an individuals other income sources (apart from this specific investment), broader personal considerations beyond personality measures (like, for example, wage income, wealth or family status) could be taken into account as determinants of anticipatory emotions.

Theoretical models are also very precise on the type of interaction between determinants and behaviour. Is there a linear relationship or is it non-linear or even non-monotonic? Do changes in determinants have an immediate impact or does it take some time before the impact on behaviour is observable? These and other qualitative properties of determinants (do determinants reinforce or dampen each other) should also provide new testable theoretical predictions. ${ }^{58}$

\subsubsection{Decision making}

Economic theory is very explicit about decision making. There is hardly any economic model where not at least one decision by some agent is made. This is also true, as an example, in the analysis of stress described above. The stressed individual follows a precise decision rule that makes her choose coping strategies in a systematic way. The framework can therefore be used to provide some answers psychologists are interested in. As an example, Gross (2008, p. 505) wrote: "one intriguing puzzle is why people use one emotion regulation strategy rather than another". Taking stress as an example of an emotion, the answer would be that personal (utility and other) costs and benefits induce an individual to decide in one way or another. The framework would e.g. allow to understand why some people predominantly use a problemfocused and others use an emotion-focused strategy.

\subsubsection{Providing structure for empirical analysis}

The theoretical framework developed in the paper by Becker and Rubinstein (2011) on terrorism is used by the authors as organizing principle for their empirical analysis. By using Israeli daily (!) data on bus ticket purchases, taxi rides (as an alternative to bus rides), visits of coffee shops and restaurants and terror attacks, they estimate the impact of terror on consumption of these goods. Going beyond their current findings, the theoretical framework developed by the authors, with some suitable extension, could be of further interest for psychological research. Reactions to a stressor (here terrorism) can take at least two forms: they can be problem-focused or emotion-focused (Lazarus and Folkman, 1984). When a theoretical framework is developed that allows individuals to choose among these approaches (or optimally allocate their resources to these approaches), one could try to identify (via structural estimation) what the optimal reaction would be to stressors. This should then also allow (being optimistic about identification

\footnotetext{
${ }^{58} \mathrm{My}$ thanks go to Agnes Moors for discussions of these points.
} 
challenges in the estimation process) to understand how much behaviour of individuals is of an objective nature and how much it is driven by non-rational/ subjective fear.

Personality analysis in the tradition of the Big Five has been critizised not to provide a theory of personality or to be too descriptive (John, Naumann and Soto, 2008, p. 140). The formal model by Wälde (2015) provides a very precise link between personality parameters and predicted behaviour. While personality parameters in this model partially capture dimensions as represented in the Big Five, it also provides additional dimensions. The advantage of such a formal model is that personality parameters can be structurally estimated using latent variable models in the tradition of Heckman et al. (2006) or Conti et al. (2014). This would allow for a theory-consistent interpretation of responses to questionnaires by providing an unambiguous interpretation to factors: personality parameters of the theoretical model represent these latent factors.

\subsubsection{Towards a classification of homo psychologicus}

The analysis of Compte and Postlewaite (2004) combines confidence affecting performance with biased perception. The individual does not perceive the true frequency $\varphi$ of success but a biased version of it. The bias could come from failures being attributed to "bad luck" and past successes being attributed to "good own performance". This would lead to a perception of $\varphi$ which is upward biased. The authors find that in the absence of any confidence channel $(\kappa=1$ in (10)), biased perception can only harm the individual. When confidence affects performance, however, a bias in perception can make the individual better off than an unbiased perception.

This points to a general principle known from micro-economics and public finance which should also be of general relevance for models of human behaviour: When we start from a firstbest economy where, by definition, there are no distortions to markets, ${ }^{59}$ any deviation from this first-best setup, i.e. any introduction of a distortion, makes the economy worse off. When we start from an economy with one distortion (e.g. environmental pollution), by contrast, one can easily imagine situations where adding a second distortion (e.g. taxation of polluting goods) makes the economy better off. This is an example of the classic Lipsey and Lancaster (1956) analysis of second-best worlds.

Applied to psychology this means that if we start from a first-best individual (starting with no distortion in perception, no distortion in storage of information, processing and so on and finishing with an optimal response), any imperfection would imply suboptimal individual wellbeing. This could be called first-best homo psychologicus. If, by contrast, we start from a second-best individual (e.g. the individual's performance is influenced by (biased) emotions), the introduction of a second imperfection (e.g. biased perception) can increase individual wellbeing.

\section{Conclusion}

Economists have always been interested in emotions. This is true for the early times of economics when utility was perceived to describe feelings of individuals about pleasure and pain. This is true for current research in behavioural economics that uses empirical measures of happiness based on questionnaires or on diary methods to quantify utility as used in theoretical analyses. And it is also true for various detailed studies of emotions (e.g. regret, rejoicing, craving, stress, anxiety, suspense, trust and guilt) and their effect on decision making.

\footnotetext{
${ }^{59}$ Classic distortions are market power (e.g. through monopolists), externalities (e.g. environmental pollution) and informational imperfections (e.g. unemployed workers do not know about all job openings and therefore need to search).
} 
From the articles surveyed here, it seems true that psychological emotion research has a strong impact on economic analyses of emotions. Many researchers cite psychological evidence to motivate their formal modelling. Economics gains a lot from this transfer of knowledge and certain behavioural regularities that could not be explained by "standard" economic models can be understood when emotions are taken into account.

This economic research on emotions is potentially of high value for psychologists. Economic theory is probably as explicit and precise in its assumptions and in the way conclusions are drawn as no other social science is. This precision should bring a lot of potential for refining psychological theory. Hopefully this will be the case in the future.

\section{A Appendix}

\section{A.1 Emotion words}

The emotion words from table 1 of Shaver et al. (1987), reproduced below, are ranked by how strongly on average individuals rate these words as describing an emotion. The table should be read first by rows. Acceptance that 'Love' describes an emotion is therefore highest, followed by 'anger' and 'hate'. 'Practicality', 'deliberateness' and 'intelligence' are the least considered to describe emotions.

\begin{tabular}{l|l|l|l} 
love & agitation & triumph & calmness \\
anger & outrage & joviality & respect \\
hate & resentment & wrath & somberness \\
depression & dislike & arousal & vehemence \\
fear & glee & attraction & sulkiness \\
jealousy & alienation & contentment & encouragement \\
happiness & distress & grumpiness & frenzy \\
passion & enjoyment & irritation & obsession \\
affection & relief & malevolence & success \\
sadness & gloom & ferocity & forgiveness \\
grief & misery & enthrallment & indignation \\
rage & euphoria & revulsion & discomfort \\
aggravation & bliss & alarm & vindictiveness \\
ecstasy & gladness & eagerness & aversion
\end{tabular}




\begin{tabular}{l|l|l|l} 
sorrow & regret & hysteria & power \\
joy & rejection & liking & vibrance \\
compassion & pride & neglect & sheepishness \\
envy & gaiety & insult & jitteriness \\
fright & homesickness & mortification & virtue \\
terror & jolliness & tenseness & mirth \\
elation & nervousness & contempt & demoralization \\
guilt & woe & amazement & fierceness \\
excitement & longing & amusement & effervescence \\
anguish & loathing & zeal & fervor \\
embarrassment & satisfaction & scorn & complacency \\
worry & hope & zest & nostalgia \\
panic & abhorrence & astonishment & modesty \\
unhappiness & insecurity & titillation & disgruntlement \\
anxiety & defeat & torment & inconsolableness \\
desire & dread & optimism & belligerence \\
horror & fondness & vengefulness & disconsolateness \\
sympathy & enthusiasm & impatience & determination \\
shame & sentimentality & persecution & doubt \\
lust & hopelessness & viciousness & superiority \\
disgust & annoyance & edginess & vanity \\
& & &
\end{tabular}

\begin{tabular}{l|l|l|l} 
hostility & cheerfulness & awe & acceptance \\
jubilation & displeasure & despondency & abandonment \\
loneliness & melancholy & gratitude & carefreeness \\
delight & glumness & mellowness & exhaustion \\
pleasure & shock & vexation & craving \\
tenderness & spite & enchantment & inclination \\
pity & suffering & exultation & approval \\
bitterness & dismay & sullenness & distraction \\
disappointment & exasperation & surprise & freedom \\
humiliation & infatuation & discontentment & startle \\
dejection & apprehension & discouragement & indecision \\
despair & caring & boredom & interest \\
frustration & isolation & exuberance & self-control \\
hurt & exhilaration & forlornness & alertness \\
adoration & rapture & lividness & carefulness \\
agony & uneasiness & moroseness & practicality \\
thrill & grouchiness & dolefulness & deliberateness \\
fury & ire & wonderment & intelligence \\
remorse & & &
\end{tabular}

Table 1 Emotion words from table 1 of Shaver et al. (1987)

\section{A.2 Journal list}

Here is the list of economics journals we take into account. They are in alphabetical order. They are the economics journals with the highest impact factor over recent years. (See the Introduction on p. 3 for selection criteria.) 
American Economic Review

Annals of Economics and Statistics

Econometrica

European Economic Review

International Economic Review

International Organizations

Journal of Business and Economic Statistics

Journal of Econometrics

Journal of Economic Theory

Journal of European Economic Association

Journal of Finance

Journal of financial Economics
Journal of health Economics

Journal of International Economics

Journal of labor Economics

Journal of Monetary Economics

Journal of Political Economy

Journal of Public Economics

Quarterly Journal of Economics

RAND journal of Economics

Review of Economic Studies

Review of Economics and Statistics

Review of financial studies

Table 2 Economics journals taken into account

\section{A.3 Anxiety, consumption and optimal investment}

This appendix provides an example for the more general setup of Caplin and Leahy (2001).

- The setup

To provide a complete setup, we repeat the budget constraints. The budget constraint of the investor in the first period (period $t$ ) reads

$$
w_{t}=c_{t}+s_{t} .
$$

The constraint in the second period (where the individual is retired and has no labour income) reads

$$
\left(1+r_{t+1}\right) s_{t}=c_{t+1}
$$

We specify a Cobb-Douglas preferences including anxiety $a_{t}$ as

$$
U=\gamma\left[\ln c_{t}-\phi \ln a_{t}\right]+(1-\gamma) E_{t} \ln c_{t+1}, \quad \gamma>0.5 .
$$

The parameter $\gamma$ describes the weight attached to utility from period $t$ as opposed to utility from period $t+1$. The parameter needs to be larger than 0.5 such that utility from the first period gets more weight. Only then individuals are impatient, i.e. they have a positive discount factor. The parameter $\phi \geq 0$ captures the strength with which the individual reacts to anticipatory emotions. When $\phi=0$, we have an "unemotional" individual, i.e. we would consider standard two-period preferences.

We assume a logarithmic Cobb-Douglas structure for anxiety as well, where a "personality parameter" $\zeta$ captures the weight of the variance as opposed to the mean,

$$
\ln a_{t}=\zeta \ln \left(\operatorname{var}_{t} c_{t+1}\right)-(1-\zeta) \ln \left(E_{t} c_{t+1}\right), \quad 0 \leq \zeta \leq 1
$$

This specification allows for positive and negative values of (the log of) anxiety. The normal case one would expect when talking about anxiety is the case with a positive value. As we can see for this equation, this is the case e.g. for $\zeta=1$ when the individual only worries about the variance. It is also the case, for a given $\zeta$ strictly smaller than 1 , when the variance is sufficiently high relative to the mean. When this is not the case or in the case of $\zeta=0$, (the $\log$ of) anxiety is negative, which means that the individual experiences pleasant anticipation and instantaneous utility in (A.3) becomes larger due to the emotions. When the variance, the mean and personality parameter $\zeta$ are such that $\ln a_{t}=0$, the positive and negative component of anticipatory emotions just balance each other. 
We can then use this description of individual feelings to study the effects of anxiety on e.g. saving behaviour. Optimal saving behaviour is obtained by maximizing the objective function (A.3) given anxiety (A.4) subject to the budget constraints (A.1) and (A.2). When an individual behaves in this way, the optimal saving is (see the web appendix for a derivation)

$$
s_{t}=\frac{1-\gamma-(3 \zeta-1) \gamma \phi}{1-(3 \zeta-1) \gamma \phi} w_{t}
$$

This equation is very helpful in deriving predictions about the optimal saving rate per se, the effect of standard preference parameters (here $\gamma$ ) and the effect of personality as captured by $\phi$ and $\zeta .^{60}$

As discussed a moment ago, we see here as well that an unemotional individual with $\phi=$ 0 displays saving behaviour which is well-known from standard intertemporal choice, $s_{t}=$ $(1-\gamma) w_{t}$. The impatience parameter $\gamma$ determines the share of first-period labour income that is used for saving. The more impatient the individual is (the higher the weight $\gamma$ on first-period consumption), the lower savings.

- Determinants of optimal investment (i)

We can easily compute the effect of the variance relative to the mean, i.e. does the individual focus on negative aspects (the "risk") and has a high $\zeta$ or does she focus on the good side (the "chances") and has a low $\zeta$ ? We find (see web appendix)

$$
\frac{d s_{t}}{d \zeta}<0
$$

Hence, as written in the main text, the more an individual is worried about the variance of the return and the less this worry reduces in the average return, the less the individual will invest.

\section{- Determinants of optimal investment (ii)}

More interesting from a psychological perspective, we can also compute the effect of a more emotional individual on savings. Formally, we find (see web appendix)

$$
\frac{d s_{t}}{d \phi}<0 \Leftrightarrow \zeta>1 / 3
$$

In words, an individual whose first-period utility reacts more strongly to anticipatory emotions ( $\phi$ rises) will save less if and only if the weight $\zeta$ on the variance is sufficiently large (larger than one third).

This is an interesting finding as it shows the complex impact of emotions on behaviour. Behaviour of a more emotional individual can be amplified or dampened: A more emotional individual can save more or less than an individual deprived of emotions. This is the case here as anticipatory emotions can have both a positive or a negative valence. If the individual worries sufficiently much, i.e. if $\zeta>1 / 3$, then the anticipatory emotion is anxiety and more anxiety leads to less savings. For the case of $\zeta<1 / 3$, anticipatory feelings are pleasant and become more emotional ( $\phi$ rises) adds positive feelings to utility in period $t$. Higher savings result as higher savings increase positive period- $t$ feelings.

\footnotetext{
${ }^{60}$ As the main text promised, the optimal saving rate is a function of preference parameters and of personality parameters. In contrast to the promise, we do not see the expected interest rate, its variance and anxiety explicitly as determinants. This is due to the simple Cobb-Douglas structure in (A.3). With a more general CES structure (see e.g. Wälde, 2012, exercise 6, p. 195), these determinants can be taken into account as well.
} 


\section{B Referees' and web appendix}

This appendix is available upon request.

\section{References}

Abdellaoui, M., C. Barrios, and P. Wakker (2007): "Reconciling introspective utility with revealed preference: Experimental arguments based on prospect theory," Journal of Econometrics, 138(1), 356-378.

Akerlof, G., and W. Dickens (1982): "The Economic Consequences of Cognitive Dissonance," American Economic Review, 72(3), 307-319.

Axarloglou, K., and V. Theoharakis (2003): "Diversity in Economics: An Analysis of Journal Quality Perceptions," Journal of the European Economic Association, 1(6), 1402-1423.

Battgalli, P., and M. Dufwenberg (2009): "Dynamic psychological games," Journal of Economic Theory, 144(1), 1-35.

Bechara, A., and A. Damasio (2005): "The somatic marker hypothesis: A neural theory of economic decision," Games and Economic Behavior, 52, 336-372.

Becker, G. (1976): "Altruism, Egoism, and Genetic Fitness: Economics and Sociobiology," Journal of Economic Literature, 14(3), 817-826.

Becker, G., and Y. Rubinstein (2011): "Fear and the Response to Terrorism: An Economic Analysis," mimeo.

Becker, G. S., and K. Murphy (1993): "A Simple Theory of Advertising as a Good or Bad," Quarterly Journal of Economics, 108(4), 961-981.

Becker, G. S., and K. M. Murphy (1988): “A Theory of Rational Addiction,” Journal of Political Economy, 96(4), 675-700.

Bell, D. E. (1982): "Regret in Decision Making under Uncertainty," Operations Research, 30(5), 941-964.

Bell, D. E. (1985): "Disappointment in Decision Making under Uncertainty," Operations Research, 33(1), 1-27.

Benjamin, D., O. Heffetz, M. Kimball, and A. Rees-Jones (2012): "What Do You Think Would Make You Happier? What Do You Think You Would Choose?," American Economic Review, 102(5), 2083-2110.

Bentham, J. (1789, 1970): An Introduction to the Principles of Morals and Legislation. Burns, J.H. and Hart, H.L.A. (eds), University of London, The Athlone Press.

Bernheim, D., and A. Rangel (2004): "Addiction and Cue-Tiggered Decision Processes," American Economic Review, 94(5), 1558-90.

Bernoulli, D. $(1738,1954)$ : "Exposition of a New Theory on the Measurement of Risk," Papers of the Imperial Academy of Sciences in Petersburg, Vol. VI, 1738, pp. 175-192. Reprinted in Econometrica, 1954, 22(1), 23-36. 
Berridge, K., and J. O'Doherty (2014): From experienced utility to decision utilitypp. 335-354. P. Glimcher and E. Fehr (Eds.), (2014), Neuroeconomics: Decisions and the brain (2nd ed.), Academic Press.

Bleichrodt, H., and P. Wakker (2015): "Regret Theory: A Bold Alternative To The Alternatives," Economic Journal, 125(583), 493-532.

Brandstätter, H., W. Güth, and H. Kliemt (2010): Psychology and Economics rather than Psychology versus Economics: Cultural differences but no barriers!pp. 11-37. Lengerich, u.a. (Eds.) Sozialpsychologie und Ökonomie: Beiträge des 25. Hamburger Symposions zur Methodologie der Sozialpsychologie, Pabst Science Publ., ISBN 978-3-89967-613-6.

Brunnermeier, M., C. Gollier, and J. Parker (2007): "Beliefs in the Utility Function - Optimal Beliefs, Asset Prices, and the Preference for Skewed Returns," American Economic Review Papers and Proceedings, 97(2), 159-165.

Brunnermeier, M., and J. Parker (2005): "Optimal Expectations," American Economic Review, 95(4), 1092-1118.

Camerer, C. F., and G. Loewenstein (2004): "Behavioral Economics: Past, Present, Future," in Advances in Behavioral Economics, Princeton: Princeton University Press.

Camerer, C. F., G. Loewenstein, and M. Rabin (2003): Advances in Behavioral Economics. Princeton University Press.

Caplin, A., and J. Leahy (2001): "Psychological Expected Utility Theory And Anticipatory Feelings," Quarterly Journal of Economics, 116(1), 55-79.

- (2004): "The supply of information by a concerned expert," Economic Journal, 114(497), 487-505.

Caplin, A., and A. Schotter (2008): The Foundations of Positive and Normative Economics: A Hand Book. Oxford Scholarship Online.

Chaiken, S., and Y. Trope (1999): Dual-process theories in social psychology. Guilford Press.

Charness, G., and M. Dufwenberg (2006): "Promises and Partnership," Econometrica, 74(6), 1579-1601.

(2011): "Participation," American Economic Review, 101(4), 1211-1237.

Clark, A., E. Diener, G. Yannis, and R. Lucas (2008): "Lags And Leads In Life Satisfaction: A Test Of The Baseline Hypothesis," Economic Journal, 118(529), F222-F243.

Clark, A., and A. J. Oswald (1994): "Unhappiness and unemployment.," Economic Journal, 104(424), 648-659.

Compte, O., and A. Postlewaite (2004): "Confidence-Enhanced Performance," American Economic Review, 94(5), 1536-1557.

Connor-Smith, J., B. Compas, M. Wadsworth, A. Harding Thomsen, and H. Saltzman (2000): "Responses to Stress in Adolescence: Measurement of Coping and Involuntary Stress Response," Journal of Consulting and Clinical Psychology, 68(6), 976-992.

Conti, G., S. Frühwirth-Schnatter, J. Heckman, and R. Piatek (2014): "Bayesian exploratory factor analysis," Journal of Econometrics, 183(1), 31-57. 
DAK (2014): Gesundheitsreport 2014. Deutsche Angestellten Krankenkasse (DAK Forschung).

DeGroot, M. H. (1970): Optimal statistical decisions. McGraw-Hill.

(2004): Optimal statistical decisions. Wiley-Interscience.

DellaVigna, S. (2009): "Psychology and Economics: Evidence from the Field," Journal of Economic Literature, 47(2), 315 - 372.

Dhami, S. (2015): Foundations of Behavioral Economic Analysis. Oxford University Press, forthcoming.

Diener, E., E. Suh, R. Lucas, and H. L. Smith (1999): "Subjective Well-Being: Three Decades of Progress," Psychological Bulletin, 125(2), 276-302.

DiTella, R., R. J. MacCulloch, and A. J. Oswald (2001): "Preferences over inflation and unemployment: Evidence from surveys of happiness," American Economic Review, 91(1), 335-341.

Dixit, A. K. (2012): "Paul Samuelson's Legacy," Annual Review of Economics, 4, 1-31.

Dufwenberg, M. (2002): "Marital investments, time consistency and emotions," Journal of Economic Behavior \& Organization, 48, 57-69.

Easterlin, R. (1974): Does Economic Growth Improve the Human Lot? Some Empirical Evidencepp. 89-125. Nations and Households in Economic Growth: Essays in Honour of Moses Abramowitz, David, P.A. and Reder, M.W. (eds), Academic Press, New York and London.

Easterlin, R. A. (2001): "Income and Happiness: Towards a Unified Theory," Economic Journal, 111, $465-484$.

Edgeworth, F. (1881, 1967): Mathematical psychics : an essay on the application of mathematics to the moral sciences. Augustus M. Kelley Publishers, New York.

Elster, J. (1998): "Emotions and Economic Theory," Journal of Economic Literature, 36(1), $47-74$.

Fehr, E., and K. Schmidt (1999): "A Theory of Fairness, Competition, and Cooperation," Quarterly Journal of Economics, 114(3), 817-868.

Frey, B. S., and A. Stutzer (2002): "What Can Economists Learn from Happiness Research?," Journal of Economic Literature, 40(2), $402-435$.

Fudenberg, D. (2006): "Advancing Beyond Advances in Behavioral Economics," Journal of Economic Literature, 44(3), 694-711.

Gawronski, B., and G. Bodenhausen (2006): "Associative and Propositional Processes in Evaluation: An Integrative Review of Implicit and Explicit Attitude Change," Psychological Bulletin, 132(5), 692-731.

Geanakoplos, J., D. Pearce, and E. Stacchetti (1989): "Psychological Games and Sequential Rationality," Games and Economic Behavior, 1(1), 60-79.

Gilboa, I. (2009): Theory of Decision under Uncertainty. Cambridge University Press.

Gilboa, I., and D. Schmeidler (1988): "Information Dependent Games," Economics Letters, 27, $215-221$. 
Glaeser, E. L. (2005): "The Political Economy of Hatred," Quarterly Journal of Economics, $120(1), 45-86$.

(2009): "Remembering Samuelson, Who Forever Fused Economics with Math," New York Times - http://economix.blogs.nytimes.com/2009/12/14/remembering-samuelson-whofused-economics-with-math.

Gollier, C. (2016): "Explaining rank-dependent utility with regret and rejoicing," mimeo.

Gollier, C., and A. Muermann (2010): "Optimal Choice and Beliefs with Ex Ante Savoring and Ex Post Disappointment," Management Science, 56(8), 1272-1284.

Gross, J. (2008): Emotion Regulation.pp. 497-512. Lewis, M. and Haviland-Jones, J. and Feldman Barrett, L. (eds.) Handbook of Emotion: New York, Guilford Press.

Gul, F. (1991): "A Theory of Disappointment Aversion," Econometrica, 59(3), 667-86.

Gul, F., and W. Pesendorfer (2008): The Case for Mindless EconomicsAndrew Caplin and Andrew Schotter (Eds.) The Foundations of Positive and Normative Economics: A Hand Book, Oxford Scholarship Online: October 2011.

Harstad, R., and R. Selten (2013): "Bounded-Rationality Models: Tasks to Become Intellectually Competitive.," Journal of Economic Literature, 51(2), 496-511.

Heckman, J., J. Stixrud, and S. Urzua (2006): "The Effects of Cognitive and Noncognitive Abilities on Labor Market Outcomes and Social Behavior," Journal of Labor Economics, $24(3), 411-482$.

Helliwell, J., R. Layard, and J. Sachs (2013): World Happiness Report. United Nations.

Holmes, T., and R. Rahe (1981): "The Social Readjustment Rating Scale," Journal of Psychosomatic Research, 11(4), 213-218.

Jevons, W. (1871, 1957): The Theory of Political Economy. H. Stanley Jevons (ed), Kelley \& Millman, INC., New York.

John, O., L. Naumann, and C. Soto (2008): Paradigm Shift to the Integrative Big Five Trait Taxonomypp. 114-158. John, O-P. and Robins, R.W. and Pervin, L.A.(eds.) Handbook of Personality: Theory and Research, New York: Guilford Press.

Kahneman, D., and A. Tversky (1979): "Prospect Theory: An Analysis of Decision under Risk," Econometrica, 47(2), 263-291.

Kahneman, D., P. Wakker, and R. Sarin (1997): "Back to Bentham? Explorations of Experienced Utility," Quarterly Journal of Economics, 112(2), 375-406.

Kalaitzidakis, P., T. Mamuneas, and T. Stengos (2003): "Rankings of Academic Journals and Institutions in Economics," Journal of the European Economic Association, 1(6), 1346-1366.

Kanner, A., J. Coyne, C. Schaefer, and R. Lazarus (1981): "Comparison of Two Modes of Stress Measurement: Daily Hassles and Uplifts Versus Major Life Events," Journal of Behavioral Medicine, 4(1), 1-39.

Köszegi, B. (2006): "Emotional Agency," Quarterly Journal of Economics, 121(1), 121-156.

Köszegi, B., and M. Rabin (2006): "A Model of Reference-Dependent Preferences," Quarterly Journal of Economics, 121(4), 1133-1165. 
Kleinginna, P., and A. Kleinginna (1981): "A Categorized List of Emotion Definitions, with Suggestions for a Consensual Definition," Motivation and Emotion, 5(4), 345-379.

Knight, F. (1921): Risk, Uncertainty, and Profit. Houghton Mifflin.

Laibson, D. (2001): "A Cue-Theory of Consumption," Quarterly Journal of Economics, 116(1), $81-119$.

Launov, A., and K. Wälde (2013): "Estimating Incentive and Welfare Effects of Non-Stationary Unemployment Benefits," International Economic Review, 54, 1159-1198.

Lawson, T. (2013): "What is this "school" called neoclassical economics?," Cambridge Journal of Economics, 37(5), 947-983.

Lazarus, R. (1999): Stress and emotion: A new synthesis. Springer Publishing Company, New York.

Lazarus, R., and S. Folkman (1984): Stress, Appraisal and Coping. Springer Publishing Company, New York.

Liner, G. (2002): "Core journals in Economics," Economic Inquiry, 40(1), 138-145.

Lipsey, R., and K. Lancaster (1956/57): "The General Theory of Second Best," Review of Economic Studies, 24, 11-32.

Loewenstein, G. (1987): "Anticipation and the Valuation of Delayed Consumption," Economic Journal, 97(387), 666-684.

Loewenstein, G. (2000): "Emotions in Economic Theory and Economic Behavior," American Economic Review, 90(2), 426 - 432.

Loewenstein, G., and J. Lerner (2003): The Role of Affect in Decision Makingpp. 619-642. Dawson, Richard J. and Scherer, Klaus R. and Goldsmith, H. Hill (eds.) Handbook of Affective Science Oxford: Oxford University Press.

Lohmann-Haislah, A. (2012): Stressreport Deutschland 2012. Bundesanstalt für Arbeitsschutz und Arbeitsmedizin.

Loomes, G., and R. Sugden (1982): "Regret Theory: An Alternative Theory of Rational Choice under Uncertainty," Economic Journal, 92(368), 805-24.

(1986): "Disappointment and Dynamic Consistency in Choice under Uncertainty," Review of Economic Studies, 53(2), 271-82.

Maio, G., and G. Haddock (2015): The psychology of attitudes and attitude change, 2nd ed. Los Angeles [u.a.] : SAGE, 2015.

Mas-Colell, A., M. D. Whinston, and J. R. Green (1995): Microeconomic Theory. Oxford University Press.

Mullainathan, S., and R. Thaler (2001): Behavioral Economicspp. 1094-1100. Neil Smelser and Paul Bates (Eds.) International Encyclopedia of the Social and Behavioral Sciences, Pergamon Press.

Neary, J. (1997): R.C. GearyŠs Contributions to Economic Theorypp. 93-118. D. Conniffe (ed.), Roy Geary, 1896-1983: Irish Statistician, Dublin: Oak Tree Press and ESRI. 
Neumann, J. v., and O. Morgenstern (1944, 1953): Theory of Games and Economic Behavior. Princeton University Press.

Ohtake, F. (2012): "Unemployment and Happiness," Japan Labor Review, 9(2), 59-74.

Passarelli, F., and G. Tabellini (2013): "Emotions and Political Unrest," CESifo Working Paper No. 4165, Category 6: Fiscal Policy, Macroeconomics and Growth.

Petty, R., S. Wheeler, and Z. Tormala (2003): Persuasion and Attitude Changepp. 353-382. T. Millon \& M. J. Lerner (Eds.), Comprehensive handbook of psychology (2nd ed). New York: John Wiley \& Sons.

Rabin, M. (1993): "Incorporating Fairness into Game Theory and Economics," American Economic Review, 83(5), 1281-1302.

(2013a): “An Approach to Incorporating Psychology into Economics," American Economic Review, 103(3), 617-622.

(2013b): "Incorporating Limited Rationality into Economics," Journal of Economic Literature, 51(2), 528-543.

Rayo, L., and G. Becker (2007): "Evolutionary Efficiency and Happiness," Journal of Political Economy, 115(2), 302-337.

Rick, S., and G. Loewenstein (2008): The Role of Emotion in Economic Behaviorpp. 138-156. Lewis, M. and Haviland-Jones, J.M. and Feldman Barrett, L. (Eds.) Handbook of Emotions, Third Edition. The Guilford Press.

Russell, J. (2014): "Four Perspectives on the Psychology of Emotion: An Introduction," Emotion Review, 6(4), 291.

Sacharin, V., K. Schlegel, and K. Scherer (2012): "Geneva Emotion Wheel Rating Study (Report)," Switzerland: University of Geneva, Swiss Center for Affective Sciences, pp. 1-13.

Samuelson, P. . (1947): Foundations of economic analysis. Harvard economic studies, Cambridge, Harvard University Press.

Savage, L. J. (1954): The Foundations of Statistics. John Wiley and Sons.

Scherer, K., A. Schorr, and T. Johnstone (2001): Appraisal Processes in Emotion: Theory, Methods, Research (Series in Affective Science). Oxford University Press, USA.

Selye, H. (1936): "A Syndrome Produced by Diverse Nocuous Agents," Nature, 138(4), 32.

Shaver, p., J. Schwartz, D. Kirson, and C. O‘Connor (1987): "Emotion Knowledge: Further Exploration of a Prototype Approach," Journal of Personality and Social Psychology, 52(6), 1061-1086.

Skinner, E., and M. J. Zimmer-Gembeck (2007): "The Development of Coping," Annual Review of Psychology, 58, 119-144.

Sobel, J. (2005): "Interdependent Preferences and Reciprocity," Journal of Economic Literature, $43(2), 392-436$.

Stevenson, B., and J. Wolfers (2008): "Economic Growth and Subjective Well-Being: Reassessing the Easterlin Paradox," Brookings Papers on Economic Activity, 39(1), 1-88. 
Stigler, G. (1950a): "The Development of Utility Theory. I," Journal of Political Economy, $58(4), 307-327$.

$373-396$.

Stiglitz, J., A. Sen, and J.-P. Fitoussi (2008): "Report by the Commission on the Measurement of Economic Performance and Social Progress," http://www.stiglitz-senfitoussi.fr/documents/rapport_anglais.pdf.

Strack, F., and R. Deutsch (2004): "Reflective and Impulsive Determinants of Social Behavior," Personality and Social Psychology Review, 8(3), 220-247.

Varian, H. (1992): Microeconomic Analysis. Norton, Third Edition.

Wakker, P. (2010): Prospect Theory For Risk and Ambiguity. Cambridge University Press.

Winter, E., L. Mendez-Naya, and I. Garcia-Jurado (2016): "Mental Equilibrium and Strategic Emotions," Management Science, forthcoming.

Wälde, K. (2012): Applied Intertemporal Optimization. Know Thyself - Academic Publishers, available at www.waelde.com/KTAP.

(2015): "Stress and Coping: An Economic Approach," mimeo Gutenberg University Mainz, available at www.waelde.com/pub.

Wälde, K., and A. Moors (2016): "Current Emotion Research in Economics," Emotion Review, forthcoming. 